\title{
Targeting Inflammatory Pathways by Flavonoids for Prevention and Treatment of Cancer
}

Authors

Affiliation
Sahdeo Prasad, Kannokarn Phromnoi, Vivek R. Yadav, Madan M. Chaturvedi, Bharat B. Aggarwal

Cytokine Research Laboratory, Department of Experimental Therapeutics, The University of Texas, M. D. Anderson Cancer Center, Houston, Texas, USA

\author{
Key words \\ - cancer \\ - inflammation \\ - flavonoids \\ - NF-KB \\ (- fruits \\ vegetables
}

\section{Abstract \\ $\nabla$}

Observational studies have suggested that lifestyle risk factors such as tobacco, alcohol, highfat diet, radiation, and infections can cause cancer and that a diet consisting of fruits and vegetables can prevent cancer. Evidence from our laboratory and others suggests that agents either causing or preventing cancer are linked through the regulation of inflammatory pathways. Genes regulated by the transcription factor NF- $k$ B have been shown to mediate inflammation, cellular trans-

\section{Introduction}

$\nabla$

Despite spending billions of dollars in research, a great deal of understanding of the causes and cell signaling pathways that lead to the disease, cancer continues to be a major killer worldwide. According to a recent statistical analysis, a total of 1479350 new cancer cases and 562340 deaths from cancer occurred in the United States in 2009 [1]. Unlike heart disease, death rates for cancer remained approximately the same in the United States from 1975 through 2002. Indeed, it is predicted that by 2020 approximately 15 million new cancer cases will be diagnosed worldwide and 12 million cancer patients will die [2]. One of the most important findings to have emerged during the past three decades is that cancer is a preventable disease. Thus, people need to be educated about the risk factors for cancer and those that prevent the disease. As many as $90 \%$ of all cancers have been shown to be due to environmental/acquired factors such as tobacco, diet, radiation, and infectious organisms, etc., and only the remaining 5-10\% of cases are caused by internal factors such as inherited mutations, hormones, and immune conditions [3].

A strong link between diet and cancer is indicated by the large variation in incidence rates of specific formation, tumor cell survival, proliferation, invasion, angiogenesis, and metastasis. Whereas various lifestyle risk factors have been found to activate NF- $k$ B and NF- $k$ B-regulated gene products, flavonoids derived from fruits and vegetables have been found to suppress this pathway. The present review describes various flavones, flavanones, flavonols, isoflavones, anthocyanins, and chalcones derived from fruits, vegetables, legumes, spices, and nuts that can suppress the proinflammatory cell signaling pathways and thus can prevent and even treat the cancer.

cancers and the observed changes in the incidence of cancer in migrating populations. For example, Ho [4] showed that although the Chinese in Shanghai will have a cancer incidence of 2 cases per 100000 population, among those who migrate to the United States, the incidence increases to 23 per 100000 within 5 years. In contrast, among US-born persons of Chinese descent the cancer incidence is 37 cases per 100000 populations, compared with 58 per 100000 among whites. This indicates that lifestyle plays a major role in the development of cancer. The important lifestyle factors that affect the incidence and mortality of cancer include tobacco, alcohol, diet, obesity, infectious agents, environmental pollutants, and radiation. All of these risk factors are linked to each other through inflammation.

Inflammation is a localized reaction of tissue to infection, irritation, or other injury. As defined by Rudolf Virchow in 1863, the key features of inflammation are redness, warmth, swelling, pain, and sometimes loss of movement or function. Inflammation is a necessary response to clear viral infections, repair tissue insults, and suppress tumor initiation/progression. However, when inflammation persists or control mechanisms are dysregulated, disease may develop, including cancer. Interestingly, inflammation functions at 
all three stages of tumor development: initiation, progression, and metastasis. During the initiation phase, inflammation induces the release of a variety of cytokines and chemokines that promote the activation of inflammatory cells and associated factors. This causes further oxidative damage, DNA mutations, and other changes in the tissue microenvironment, making it more conducive to cell transformation, increased survival, and proliferation. At the molecular level, inflammation, transformation, survival, and proliferation are regulated by nuclear factor $k \mathrm{~B}(\mathrm{NF}-k \mathrm{~B}), \mathrm{a}$ family of ubiquitously expressed transcription factors. NF- $k B$ is activated by various inducers such as tobacco, alcohol, infections, ionizing radiation, environmental pollutants, chemotherapeutic agents, and tumor necrosis factor- $\alpha$ (TNF- $\alpha$ ). TNF- $\alpha$ is also one of the prime signals that induces apoptosis in many different types of cells. Whereas acute activation of NF- $\kappa$ B may be therapeutic, chronic activation may lead to the development of chronic inflammation, cancer, and other chronic diseases. NF- $k$ B has been associated with increased survival in many tumor cells; thus, its inhibition could be a novel approach to breaking the vicious cycle of tumor cell proliferation.

\section{What is NF-kB?}

$\nabla$

NF- $k$ B was first identified in 1986 by Sen and Baltimore [5]. In its resting stage, this factor resides in the cytoplasm as a heterotrimer consisting of $\mathrm{p} 50, \mathrm{p} 65$, and $\mathrm{I} k \mathrm{~B} \alpha$. The inhibitor $\mathrm{I} k \mathrm{~B} \alpha$ masks the NF- $k$ B nuclear localization domain and inhibits its DNA-binding activity. In response to a large variety of stimuli, the I $k \mathrm{~B}$ inhibitor is rapidly phosphorylated and degraded. This allows NF- $k \mathrm{~B}$ nuclear translocation, DNA binding to specific recognition sequences in promoters, and transcription of the target genes [6, 7]. The kinase that causes the phosphorylation of $\mathrm{I} k \mathrm{~B} \alpha$ is called I $k \mathrm{~B} \alpha$ kinase (IKK). IKK $\beta$ mediates the classic/canonical NF- $k \mathrm{~B}$ activation pathway, and IKK $\alpha$ mediates the non-canonical pathway. On activation, NF- $k$ B induces the expression of more than 400 genes that have been shown to suppress apoptosis and induce cellular transformation, proliferation, invasion, metastasis, chemoresistance, radioresistance, and inflammation [8,9]. The activated form of NF- $k$ B has been found to mediate different diseases, including cancer $[8,10]$, atherosclerosis [11], myocardial infarction [12], diabetes [13] allergy [14,15], asthma [16], arthritis [17], Crohn's disease [18], multiple sclerosis [19], Alzheimer's disease [20,21], osteoporosis, psoriasis, septic shock, AIDS, and other inflammatory diseases [22,23]. It is not surprising that most of these diseases are caused by dysregulated inflammation [24]. Most of the traditional chemotherapeutic agents induce NF-kB, and subsequently make the tumors resistant to the drugs. Also, constitutive activation of NF-kB has been linked with chemoresistance and poor prognosis. Therefore, the flavonoids and other phytochemicals, which inhibit deregulated activation of $\mathrm{NF}-\kappa \mathrm{B}$, offer a good promise for cancer prevention and therapy. Therefore, agents are needed that can suppress inflammation through inhibition of NF- $k$ B activation, which could potentially prevent or delay the onset of or treat NF- $k$ B-linked diseases. Much evidence indicates that certain constituents of fruits, vegetables, nuts, legumes, and spices can downregulate inflammation and most chronic diseases (see $\bullet$ Fig. 1). Flavonoids are one category of nutraceuticals present in these dietary products that can suppress inflammation and thus play an important role in inflammation-related diseases, including cancer. Flavonoids are believed to suppress inflammation, transformation, proliferation, survival, invasion, and angiogenesis. Those that can suppress carcinogenesis are discussed in detail below.

\section{Association of Inflammation with Cancer}

$\nabla$

There is a strong association between chronic inflammatory conditions and cancer specific to the organ. Epidemiological evidence points to a connection between inflammation and a predisposition for the development of cancer, i.e., long-term inflammation leads to the development of dysplasia. Various factors are known to induce chronic inflammatory responses that further cause cancer. These include bacterial, viral, and parasitic infections (e.g., Helicobacter pylori, Epstein-Barr virus, human immunodeficiency virus, flukes, schistosomes), chemical irritants (i.e., tumor promoters, such as phorbol ester 12-O-tetradecanoyl-13phorbol acetate, also known as phorbol myristate acetate), and non-digestible particles (e.g., asbestos, silica) [25,26]. Epidemiological studies estimate that nearly $15 \%$ of the worldwide cancer incidence is associated with microbial infection [27].

It is mechanistically proven that inflammation produces reactive oxygen species (ROS) and reactive nitrogen species (RNS). In particular, ROS and RNS lead to oxidative damage and nitration of DNA bases, which increases the risk of DNA mutations and further leads to cancer [28]. The most thoroughly studied examples of inflammation and cancer are chronic inflammatory bowel disease and the increased risk of colorectal cancer, chronic gastritis resulting from $H$. pylori infection and gastric adenocarcinoma, and chronic hepatitis and liver cancer. Chronic hepatitis B infection leads to about a 10 -fold increase in the risk of liver cancer [29].

Inflammation results in the recruitment of leukocytes secreting a variety of proliferative cytokines and angiogenic factors to the site of tissue insult. These cytokines are known to be required for proper wound healing, and stimulate epithelial cell proliferation; however, if these are uncontrolled they could lead to dysplasias and ultimately cancer. Tumor cells themselves also produce various cytokines and chemokines that attract leukocytes, which in turn produce cytokines and chemokines that stimulate further tumor cell proliferation. Paradoxically, cytokine deficiency (e.g., GM-CSF, IL-2 and IFNY) can also lead to tumor development. Immune homeostasis consists of a succession of pro- and anti-inflammatory signals. Loss of the anti-inflammatory signals leads to chronic inflammation and proliferative signaling.

The cytokines and chemokines secreted by tumor-associated macrophages and leukocytes cause metastasis and angiogenesis of cancer cells. These cytokines and chemokines promote cell motility and induce the growth of tumor-associated vessels. The leukocytes also promote angiogenesis by inducing vessel dilation and extravasations of tumor cells. Inflammation also promotes the establishment of metastases.

\section{Biosynthesis and Metabolism of Flavonoids $\nabla$}

The typical flavone backbone in the flavonoids resembles other cognate heterocyclic molecules, which possess a flavin-like ring; and the word "flavin" is derived from the Latin word flavus, which means "yellow". It is the most common group of polyphenolic compounds, and their metabolites account for much of the red, blue, purple, and other color pigmentation in plants [30] (see - Fig. 1). This class was the first to be termed "bioflavonoids." The 


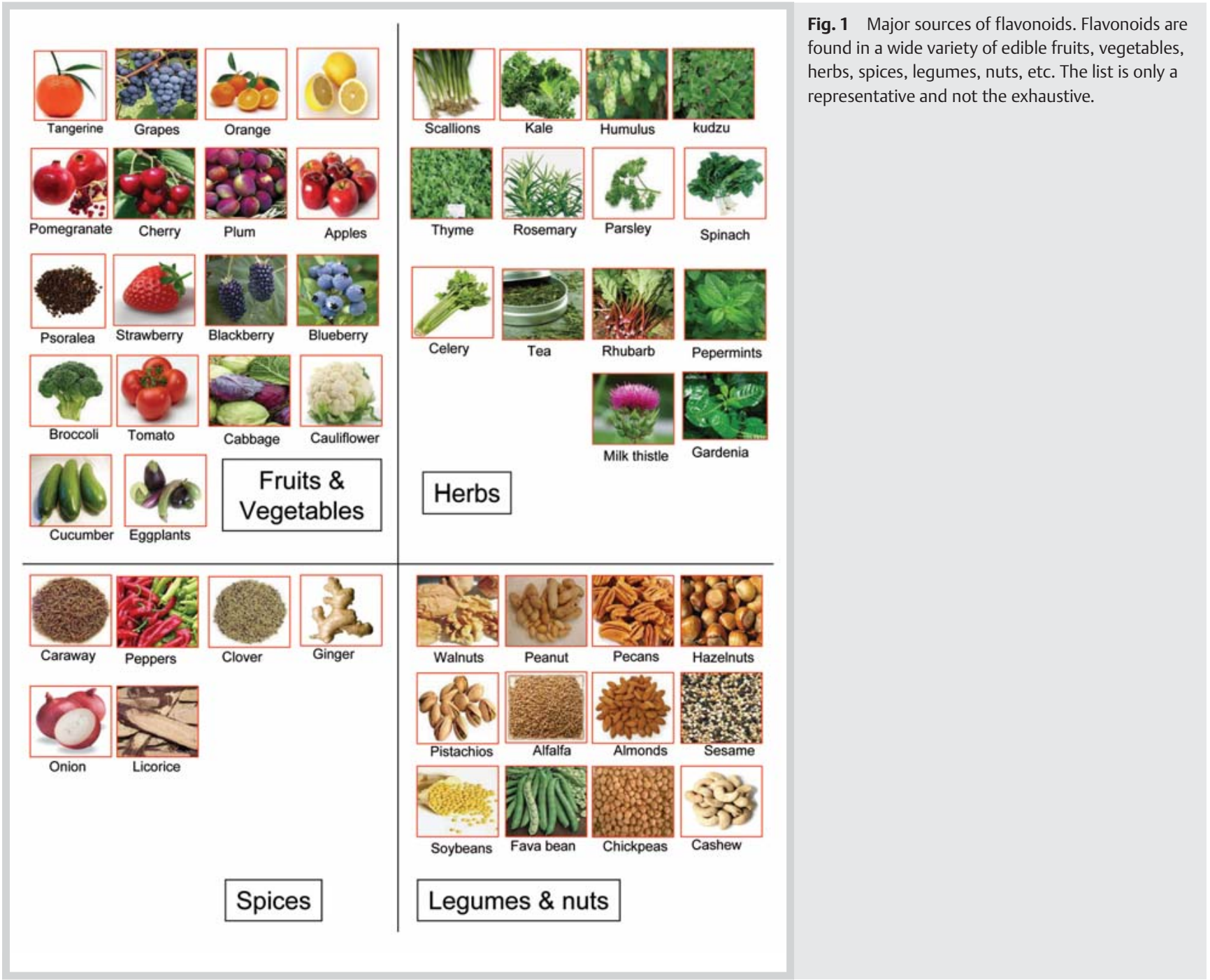

health benefits of wine, chocolates, fruits, vegetables, nuts, spices, and legumes are attributable to their flavonoids ( Table 1 ). Until 50 years ago, the mechanisms of flavonoids were hardly known. However, now it is widely known that flavonoids possess a broad spectrum of biological activity [31]. For example, flavonoids modify the body's reaction to allergens, viruses, and carcinogens. They also have antiallergic, anti-inflammatory, antimicrobial, and anticancer activity. Although it is unclear how flavonoids protect against cancer, many of their biological actions have been attributed to their anti-inflammatory and antioxidant activities.

Flavonoids constitute a relatively diverse family of aromatic molecules that are derived from Phe and malonyl-coenzyme $\mathrm{A}(\mathrm{CoA})$. This malonyl-CoA yields the true backbone of flavonoids. According to IUPAC nomenclature based on structure, flavonoids are classified into three groups, i.e., flavones, isoflavones and neoflavones. These three flavonoid classes are all ketone-containing compounds. The flavonoids and bioflavonoids also contain nonketone polyhydroxy polyphenol compounds which are more specifically termed flavanoids, flavan-3-ols, or catechins (although catechins are actually a subgroup of flavanoids). In general, flavonoids include six major subgroups that are found in most of the higher plants. These are chalcones, flavones (generally in herbaceous families, e.g., Labiatae, Umbelliferae, Compositae), flavonols (generally in woody angiosperms), flavanones, anthocya- nins, and isoflavonoids. A seventh group, the aurones, is widespread but not ubiquitous. The flavonoid aglycone consists of a benzene ring $(A)$ condensed with a six-membered ring $(C)$, which in the 2-position carries a phenyl ring (B) as a substituent ( Fig. 2). The six-membered ring condensed with the benzene ring is either an $\alpha$-pyrone (flavonols and flavonones) or its dihydro derivative (flavanols and flavanones). The position of the benzenoid substituent divides the flavonoid class into flavonoids (2-position) and isoflavonoids (3-position). Flavonols differ from flavonones by a hydroxy group at the 3 -position and $\mathrm{C}=\mathrm{C}$ double bond [32]. Flavonoids, collectively known as vitamin P and citrin, are a class of plant secondary metabolites. They usually consist of two benzene rings joined together with a short three-carbon chain ( Fig. 2). One of the carbons of the short chain is connected to the carbon of one of the benzene rings, either directly or through an oxygen bridge, thus forming a third middle ring, which can be five- or six-membered. Fig. 3 shows the different flavonoids in fruits, vegetables, legumes, nuts, spices and other herbs. The biosynthesis of flavonoids occurs in the cytoplasm through a series of enzymes found in membranes of the endoplasmic reticulum [33].

The pathway involved in biosynthesis is called the phenylpropanoid metabolic pathway. In this pathway phenylalanine, an amino acid, produces 4-coumaroyl-CoA [34] which is combined with 
Table 1 Dietary flavonoids and their sources.

\begin{tabular}{|c|c|c|}
\hline Flavonoid category & Dietary flavonoids & Sources \\
\hline Chalcones & $\begin{array}{l}\text { isoliquiritigenin, cardamomin, butein, 2'-hydroxychalcone, } \\
\text { resveratrol, tris(methoxymethoxy)chalcone, xanthohumol }\end{array}$ & licorice, cashews, humulus, grapes, red wine \\
\hline Flavanones & $\begin{array}{l}\text { hesperetin, naringenin, naringin, eriodictyol, homoeriodictyol, } \\
\text { poncirin, silibinin, bavachinin taxifolin }\end{array}$ & oranges, grapes, lemons, psoralea, milk thistle \\
\hline Flavonols & quercetin, kaempferol, myricetin, isorhamnetin, morin, fisetin & $\begin{array}{l}\text { onions, scallions, kale, broccoli, apples, berries, tea, tomatoes, } \\
\text { cherries, spinach, almonds, cucumbers }\end{array}$ \\
\hline Flavones & $\begin{array}{l}\text { apigenin, luteolin, diosmetin, baicalein, wogonin, amentoflavone, } \\
\text { biapigenin, baicalin, flavopiridol, isovitexin, ochnaflavone, acace- } \\
\text { tin, chrysin, tangeretin, pentamethoxyflavone, gossypin, nobiletin }\end{array}$ & $\begin{array}{l}\text { parsley, thyme, celery, peppers, sesame, alfalfa, rosemary, toma- } \\
\text { toes, thyme, tangerines, gardenia, oranges }\end{array}$ \\
\hline Isoflavonoids & $\begin{array}{l}\text { daidzein, genistein, glycitein, vitexin, irigenin, glabridin, equol, } \\
\text { biochanin A, formononetin, coumestrol, nobiletin }\end{array}$ & $\begin{array}{l}\text { soybeans, chickpeas, alfalfa, barley, broccoli, cauliflower, caraway, } \\
\text { red clover, oranges, peanuts, fava beans, kudzu }\end{array}$ \\
\hline Anthocyanidins & cyanidin, delphinidin, malvidin, pelargonidin, peonidin, petunidin & $\begin{array}{l}\text { berries, grapes, cherries, plums, pomegranates, eggplant, cab- } \\
\text { bage, rhubarb, almonds, cashews, hazelnuts, pecans, pistachios, } \\
\text { peanuts, walnuts, fava beans, kudzu, psoralea, blueberries, bil- } \\
\text { berries, mulberries, black raspberries }\end{array}$ \\
\hline
\end{tabular}

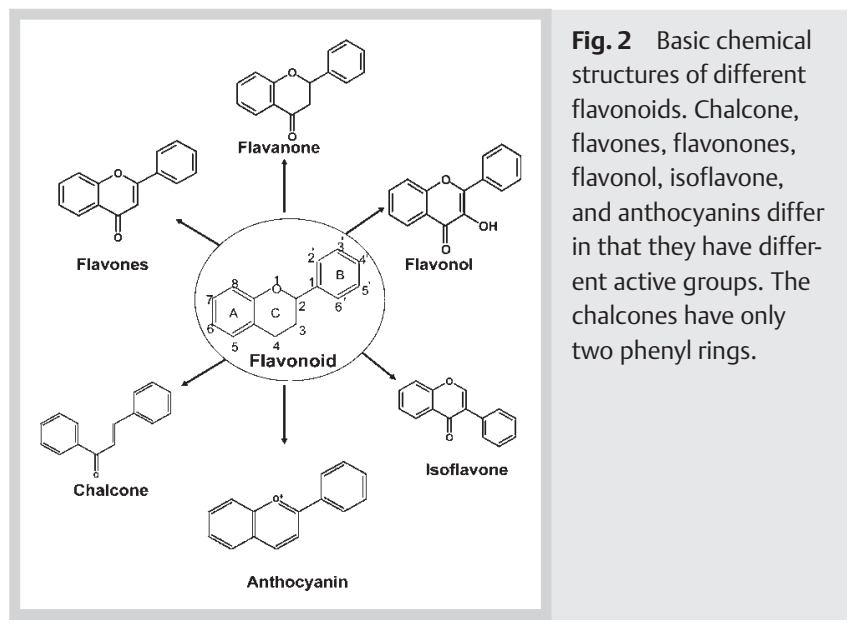

malonyl-CoA. Chalcones contain two phenyl rings. They possess the monohydroxylated ring typical of all flavonoids. Flavanones, which are the important intermediates and branch point compounds in flavonoid biosynthesis, often occur in plants as glycosides. Flavones are known to arise by oxidative processes from flavanones. The oxidation of flavanones to flavones is catalyzed by an enzyme, flavone synthase, introducing a double bond between carbon atoms 2 and 3 of the third ring.

Interestingly, the biosynthesis of flavone is carried out by two completely different flavone synthases: flavone synthase I and flavone synthase II. Anthocyanin is synthesized by anthocyanidin synthase (ANS), a 2-oxoglutarate iron-dependent oxygenase, which catalyzes the penultimate step in its biosynthesis [35]. The synthesis of anthocyanidins is mediated through in vitro conversion of leucoanthocyanidins to dihydroflavonol and flavonol intermediates (cis- and trans-isoforms) catalyzed by ANS [36]. It has been shown that colored anthocyanidins such as pelargonidin and cyanidin are synthesized from colorless leucoanthocyanidins (leucopelargonidin and leucocyanidin) by the ANS-catalyzed reaction in the presence of ferrous ion, 2-oxoglutarate, and ascorbate, followed by acidification with $\mathrm{HCl}$ [37]. The other enzyme of the pathway, flavonoid 3-O-glucosyltransferase, is considered a final enzyme necessary for producing the stable anthocyanin molecules in plant cells [38].
When administered to rodents or humans, flavonoids have a relatively low bioavailability because of their limited absorption and rapid elimination. However, bioavailability differs among the various classes. It has been observed that isoflavones have the highest bioavailability, whereas flavonols (proanthocyanidins and tea catechins) and anthocyanins are very poorly absorbed [39]. Furthermore, it has been reported that even after cooking, most flavonoid glycosides reach the small intestine intact. Flavonoids are absorbed in the small intestine, where they are rapidly metabolized to form methylated, glucuronidated, or sulfated metabolites [39].

Hollman et al. [40] conducted a study to examine the absorption of quercetin (highly present in onions, particularly red onions) among nine patients who had undergone ileostomy. Patients received a quercetin-free diet for 12 days and were then randomized to receive one of the following supplemented diets over a 12-day period: $225 \pm 43$ (S.D.) $\mu \mathrm{mol}$ of fried onions ( $68 \pm 13 \mathrm{mg}$ quercetin glucosides), pure quercetin rutinoside (the major quercetin glycoside found in tea), or pure quercetin aglycone. The absorption of quercetin aglycone was found to be approximately $24 \%$, whereas that of quercetin glycosides from onions was $52 \%$. This study suggested that the glycoside moiety is present in quercetin enhanced absorption.

In another study on 12 men with benign prostatic hyperplasia, soy extract (3 Evestrel capsules), providing a total of $112.5 \mathrm{mg}$ equiv./day of the isoflavone aglycone, was given for 3 days before prostate surgery. The metabolites were identified in blood and prostate tissues using electrospray ionization-liquid chromatography-tandem mass spectrometry. The concentration of total isoflavones in the prostate tissues was $1.05 \mathrm{nmol} / \mathrm{g}$. However, concentrations in the prostate were lower than those in plasma in all volunteers: $0.47 \mu \mathrm{m}$ vs. $0.66 \mu \mathrm{M}$ for daidzein and $0.58 \mu \mathrm{m}$ vs. $0.78 \mu \mathrm{M}$ for genistein [41].

A study on a group of patients fed with 4 slices of bread containing soy grits $50 \mathrm{~g} /$ slice $(n=8)$ showed a statistically significant decrease in serum PSA concentrations compared with the control group that ingested a similar wheat bread without the soy supplementation $(n=8)$ [42]. A double-blind, placebo-controlled study was conducted in patients with high-grade prostatic intraepithelial neoplasia (HGPIN). The patients were administered $600 \mathrm{mg} /$ day of mixed green tea catechins. The first-year followup of the 5-year study reported that the conversion rate from HGPIN to prostate cancer was $3 \%$ in the experimental group and 


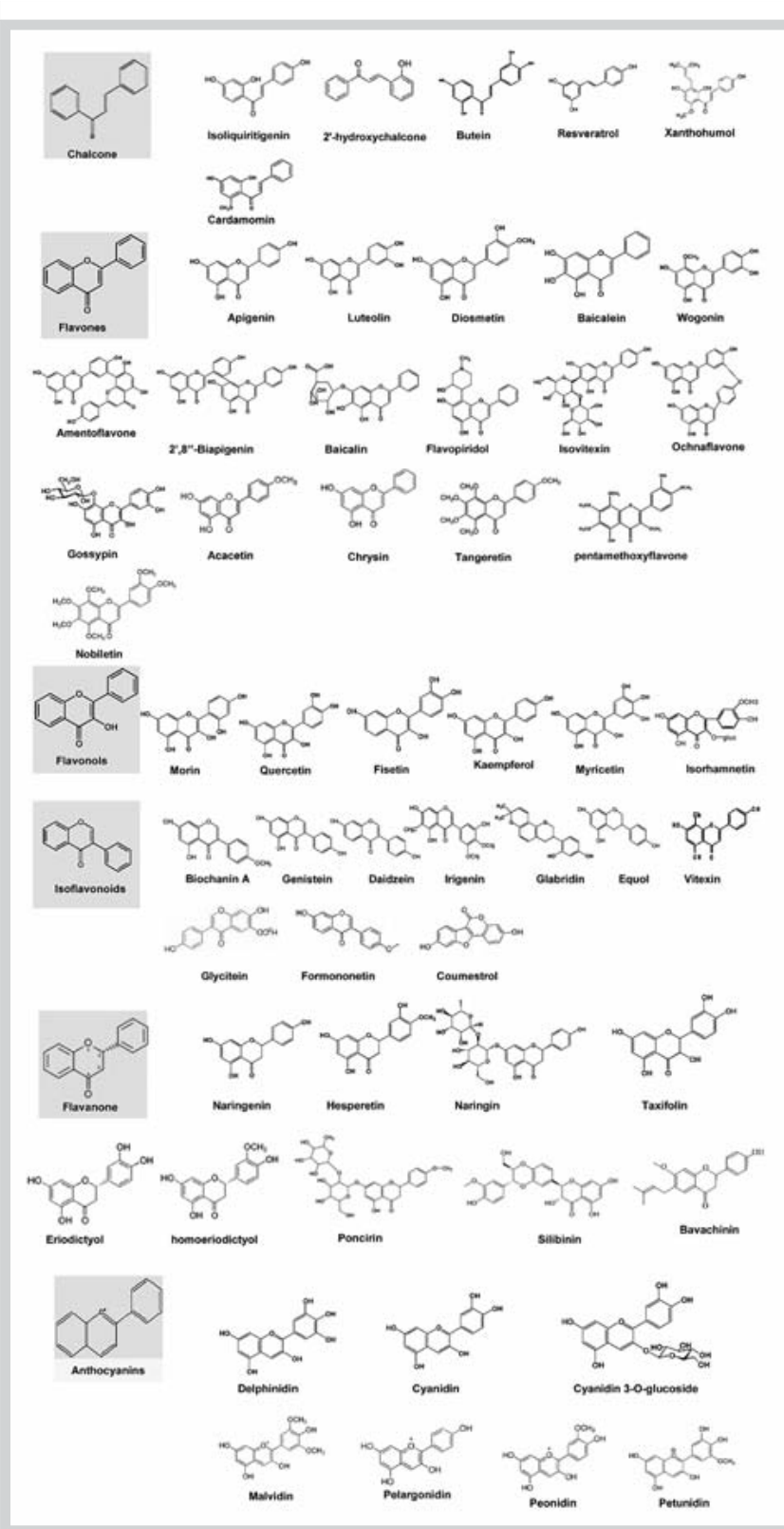

Fig. 3 Chemical structures of naturally occurring different types of flavonoids present in different fruits, vegetables herbs, spices, legumes, nuts, etc.

$30 \%$ in the control group; however, no significant change was observed in total prostate-specific antigen (PSA) between the 2 arms [43].

Silibinin, also known as silybin, is the major active constituent of silymarin, the mixture of flavonolignans extracted from blessed milk thistle (Silybum marianum). In a clinical trial designed to assess the toxicity, silybin was administered orally to 13 prostate cancer patients, giving 2.5-20 g daily, in three divided doses. It was concluded that $13 \mathrm{~g}$ of oral silybin daily, in 3 divided doses, appeared to be well tolerated in patients with advanced prostate cancer, and was recommended as the phase II dose [44]. Furthermore, in 6 prostate cancer patients who received $13 \mathrm{~g}$ of silybin daily for 14-31 days (mean was 20 days) and six additional participants serving as control subjects showed increased absorption of silibilin. In contrast to the high peak levels of silibinin ob- served in blood, the highest silibinin level observed in the harvested prostate tissue was $496.6 \mathrm{pmol} / \mathrm{g}$. There were no significant differences noted in baseline and posttreatment blood levels of IGF-I and IGFBP-3. One of the treated patients developed a grade 4 postoperative thromboembolic event. The other observed toxicities in the treatment group were mild: four subjects had diarrhea and one had asymptomatic grade 2 hyperbilirubinemia which was transient [45].

The absorption of naringenin and its glycosides was studied by Felgines et al. [46] in rats given either a single dose or doses for 14 days. They observed that absorption of naringenin and naringenin 7-glucoside was similar in intestine and cecum, whereas naringenin 7-rhamnoglucoside exhibited delayed absorption, resulting in decreased bioavailability. Adaptation to flavanone diets did not induce the accumulation of naringenin in plasma. Moreover, flavanone cecal content markedly decreased after adaptation, and almost no naringenin 7-rhamnoglucoside was recovered after naringenin 7-rhamnoglucoside feeding, which suggests an adaptation of cecal microflora. Overall, these studies indicate that flavanones are efficiently absorbed after feeding to rats and human beings and that their bioavailability is related to their glycosidic moiety.

Interestingly, different flavonoinds effectively inhibit NF- $k \mathrm{~B}$ and other inflammatory responses, in spite of having different bioavailability. This raises an interesting question that possibly, the in vitro and the in vivo effective concentrations are not the same. It is quite likely that an effective in vitro concentration may never be observed in vivo for a given compound, but still the compound may be effective in inhibiting inflammatory processes. Alternatively, it is also possible that the mechanisms through which these molecules function in vitro and in vivo are quite different. Flavonoids are mostly derived from fruits, vegetables, and edible plants and are considred safe, but they do show toxicity when given in high doses. Son et al. [47] also revealed that small doses of phytochemicals ingested by humans are not toxic and instead induce mild cellular stress responses. Another flavonoid, quercetin, did not show toxicity when administered orally to male rats to a dose up to $2000 \mathrm{mg} / \mathrm{kg}$ body weight, probably because in vivo these compounds are metabolized and made available at lower doses [48].

\section{Molecular Targets of Flavonoids \\ $\nabla$}

The human genome is made up of approximately 25000 genes, approximately 3000 of which are linked with a total of 153 signaling pathways. More than 350 genes have been linked with any given cancer, indicating that cancer is a complex disease involving interactions between multiple genes that up- or downregulate undesired protein products. Therefore, there is a need for novel and effective chemopreventive and chemotherapeutic drugs that normalize modulated genes. Modulation of the most common cellular responses, such as inflammation, proliferation, apoptosis, metastasis and angiogenesis, by flavonoids is discussed below.

Suppression of inflammatory pathways by flavonoids Different flavonoids have a wide range of targets that lead to suppression of inflammation ( Fig.4), which has been closely linked to cancer ( Table 2 ).

Regulation of inflammatory pathways by chalcones: Chalcones (1,3-diphenyl-2-propenones) are anti-inflammatory and cancer 


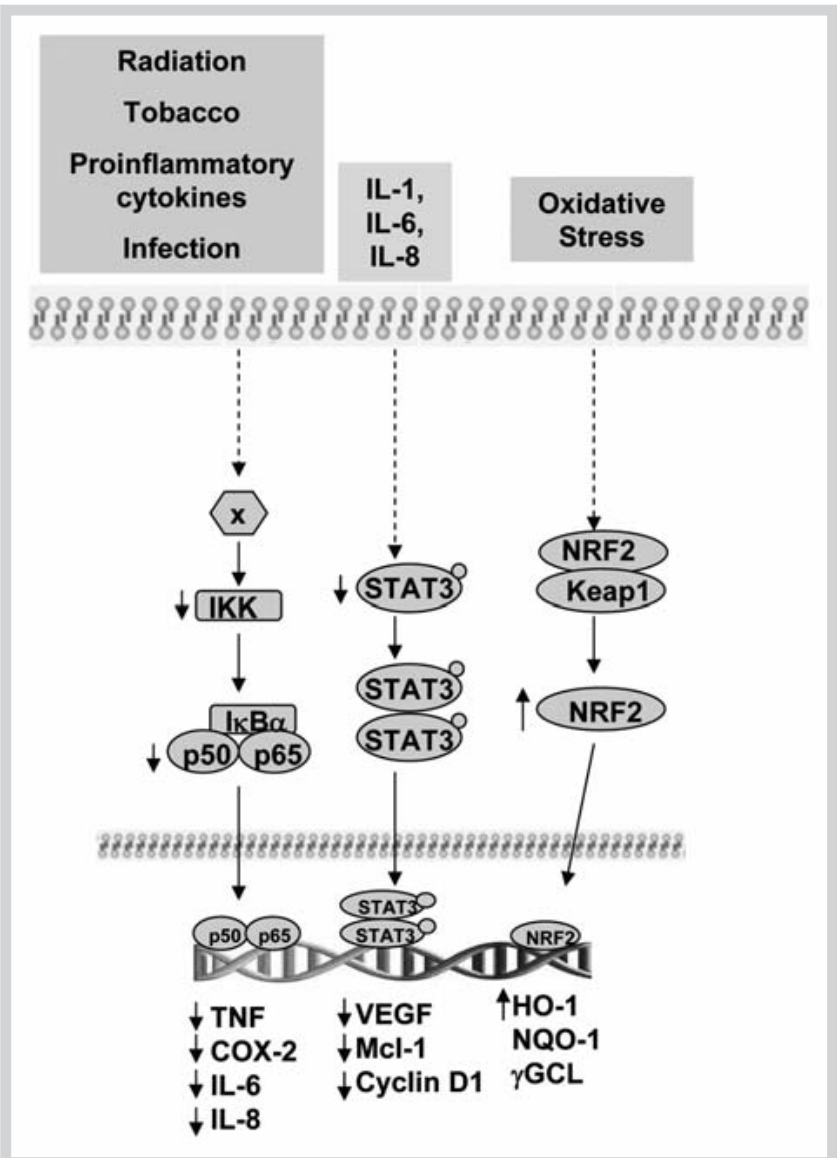

Fig. 4 Major molecular targets of flavonoids for regulation of inflammatory pathways. Down and up arrow indicates the inhibition and induction, respectively, of the targets.

preventive food components found in a human diet rich in fruits and vegetables. Chalcone induces the mitochondrial pathway of apoptosis and inhibits the NF- $k$ B inflammatory system in T24 and HT-1376 cells [49]. In IL-6- and LPS-treated endothelial cells, chalcone has been found to abrogate inflammation by inhibiting the activation of STAT3 and NF- $k$ B. Chalcone also upregulates levels of the transcription factor Nrf2 in nuclear extracts and increases antioxidant response element (ARE)-luciferase and thioredoxin reductase promoter activity in endothelial cells [50]. Isoliquiritigenin with a chalcone structure, an active component present in plants such as Glycyrrhiza and Dalbergia spp., shows various biological activities, including anti-inflammatory activity. Isoliquiritigenin was found to inhibit NF- $k B$ activation in endothelial cells by blocking the phosphorylation and subsequent degradation of $I k B \alpha[9]$. The chalcone derivative 2'-hydroxychalcone showed anti-inflammatory action in LPS-induced inflammation in RAW 264.7 macrophages via activation of the HO-1 pathway [51]. In these cells, cardamomin (2',4'-dihydroxy-6'-methoxychalcone) from Alpinia conchigera Griff (Zingiberaceae) also inhibited LPS-induced NF- $\kappa$ B activation.

Another chalcone, cardamomin, inhibited not only LPS-induced degradation and phosphorylation of $\mathrm{I} \kappa \mathrm{B} \alpha$ but also activation of IKK and nuclear translocation of NF- $k \mathrm{~B}$ [52]. Other chalcone derivatives, such as 2'-hydroxy-4'-methoxychalcone, 2',4-dihydroxy4'-methoxychalcone, and 2',4-dihydroxy-6'-methoxychalcone, also inhibited LPS-induced NF- $k$ B. The inhibition of NF- $k$ B was
Table 2 Molecular targets of flavonoids in inhibition of inflammation.

\begin{tabular}{|c|c|}
\hline Flavonoids & Targets \\
\hline \multicolumn{2}{|l|}{ Chalcone } \\
\hline - isoliquiritigenin & $\downarrow N F-\kappa B$ \\
\hline - 2'-hydroxychalcone & $\uparrow \mathrm{HO}-1$ \\
\hline Cardamomin & $\downarrow N F-K B, \downarrow I K K$ \\
\hline $\begin{array}{l}\text { tris(methoxymethoxy) } \\
\text { chalcone }\end{array}$ & $\downarrow$ NO, $\downarrow$ iNOS \\
\hline butein & $\downarrow N F-K B, \downarrow I K K$ \\
\hline - xanthohumol & $\downarrow N F-K B, \downarrow I K K$ \\
\hline \multicolumn{2}{|l|}{ Flavones } \\
\hline fisetin & $\downarrow N F-K B, \downarrow I K K$ \\
\hline gossypin & $\downarrow N F-K B, \downarrow I K K$ \\
\hline - luteolin & $\downarrow N F-K B$ \\
\hline acacetin & $\downarrow N F-\kappa B$ \\
\hline > apigenin & $\downarrow \mathrm{NF}-\kappa \mathrm{B}, \uparrow \mid \kappa \mathrm{B} \alpha$ \\
\hline \multicolumn{2}{|l|}{ Flavonols } \\
\hline quercetin & $\downarrow$ NF-KB, $\downarrow$ AP-1 \\
\hline myricetin & $\downarrow \mathrm{COX}-2, \downarrow \mathrm{NF}-\mathrm{KB}$ \\
\hline > kaempferol & $\downarrow \mathrm{PGE} 2, \downarrow$ COX-2, $\downarrow$ NF-KB \\
\hline D isorhamnetin & $\downarrow N F-K B, \downarrow$ STAT- 1 \\
\hline \multicolumn{2}{|l|}{ Flavanones } \\
\hline naringenin & $\downarrow$ iNOS, $\downarrow$ NO, $\downarrow$ NF-kB,$\downarrow$ STAT- 1 \\
\hline poncirin & $\begin{array}{l}\downarrow \mathrm{PGE}_{2}, \downarrow \text { IL- } 6, \downarrow \text { iNOS, } \downarrow \text { COX-2, } \\
\downarrow \text { NF-kB-DNA binding }\end{array}$ \\
\hline hesperetin & $\downarrow N F-k B, N I K / I K K, ~ E R K, ~ p 38$ and JNK \\
\hline silibinin & $\downarrow N F-k B, \downarrow$ NF-kB-DNA binding, $\downarrow$ COX-2 \\
\hline taxifolin & $\downarrow$ ICAM-1 \\
\hline \multicolumn{2}{|l|}{ Anthocyanins } \\
\hline cyanidin 3-rutinoside & $\downarrow N F-\kappa B, \downarrow c-J u n$ \\
\hline cyanidin 3-glucoside & $\downarrow N F-k B, \downarrow c-J u n$ \\
\hline cyanidin & $\downarrow$ c-Jun, $\downarrow$ NF-kB, $\downarrow \mathrm{PGE}_{2}, \downarrow$ COX-2 \\
\hline delphinidin & $\downarrow N F-k B, \downarrow$ IKK \\
\hline malvidin & $\downarrow$ IL-6 secretion \\
\hline \multicolumn{2}{|l|}{ Isoflavonoids } \\
\hline genistein & $\downarrow$ NF-kB, $\downarrow$ NF-kB-DNA binding, $\uparrow$ IKB $\alpha, \downarrow$ IL-8 \\
\hline - daidzein & $\downarrow$ NF-KB, $\downarrow$ STAT- $1, \downarrow$ iNOS \\
\hline glabridin & $\downarrow N F-K B, \downarrow N O$ \\
\hline irigenin & $\downarrow$ iNOS, $\downarrow$ COX-2, $\downarrow$ NF-kB \\
\hline tangeretin & $\downarrow$ COX-2, $\downarrow$ NF-KB \\
\hline nobiletin & $\downarrow$ iNOS, $\downarrow$ COX-2 \\
\hline
\end{tabular}

NF-kB, nuclear factor-kappaB; IkB $\alpha$, inhibitor of kappaBalpha; HO-1, hemeoxygenase-1; NO, nitric oxide; AP-1, activator protein-1; COX-2, cyclooxygenase-2; IL-8, interleukin-8; iNOS, inductible nitric oxide synthase

found to be mediated through inhibition of $\mathrm{I} \kappa \mathrm{B} \alpha$ degradation and the phosphorylation of c-jun $\mathrm{N}$-terminal kinase (JNK) and cjun [53]. The synthetic chalcone derivatives 2'-methoxy-3,4-dichlorochalcone and 2'-hydroxy-3-bromo-6'-methoxychalcone were also reported to suppress the NF- $k$ B activation in LPStreated RAW 264.7 cells [54]. The synthetic chalcone 2',4',6'-tris (methoxymethoxy)chalcone showed anti-inflammatory activities by decreasing the degradation of $I k B \alpha$, which further inhibited NF- $\mathrm{kB}$ translocation into the nucleus; it also reduces nitric oxide (NO) production by inhibition of inducible NO synthase (iNOS) expression in LPS-activated RAW 264.7 macrophages [52]. Regulation of inflammatory pathways by flavones: Flavones are a class of flavonoids with a backbone of 2-phenylchromen-4-one (2-phenyl-1-benzopyran-4-one). Flavones are mainly found in cereals and herbs and cause yellow pigments in plants. Natural flavones include apigenin, luteolin, tangeritin, chrysin, baicalein, scutellarein, wogonin, and fisetin. Two synthetic flavones are di- 
osmin and flavoxate. Flavones have several putative beneficial effects against a number of diseases, such as atherosclerosis, osteoporosis, diabetes mellitus, inflammation, and cancers.

We have shown that fisetin, present in vegetables and fruits such as strawberry, apple, persimmon, grape, onion, and cucumber and wine, is a potent inflammatory agent through its suppression of NF- $k$ B activation induced by various inflammatory agents and carcinogens. The inhibition of NF- $k$ B was found to be mediated through blocking of phosphorylation and degradation of $\mathrm{I} k \mathrm{~B} \alpha$ by inhibiting IKK activation and suppression of the phosphorylation and nuclear translocation of p65 [55]. Gossypin, a flavone originally isolated from Hibiscus vitifolius, has been shown to suppress inflammation as well as angiogenesis and carcinogenesis. In one study we have shown that gossypin inhibited NF- $k \mathrm{~B}$ activation as induced by inflammatory stimuli and carcinogens. It also inhibited constitutive NF- $k$ B activation in tumor cells. The NF$\kappa \mathrm{B}$ inhibition by gossypin was also found to be mediated through inhibition of IKK, which led to the suppression of $\mathrm{I} k \mathrm{~B} \alpha$ phosphorylation and degradation, p65 nuclear translocation, and NF- $k$ Bregulated gene expression [56]. The flavone luteolin effectively suppressed NF- $\kappa$ B induced by TNF in lung cancer cells [57]. Acacetin (5,7-dihydroxy-4'-methoxyflavone) was also found to have anti-inflammatory and antiperoxidative effects in RAW 264.7 cells activated with LPS. One study showed that treatment with acacetin reduced the translocation of NF- $k \mathrm{~B}$. The activation of NF- $k B$ was inhibited by prevention of the degradation of $I k B$ [58]. Apigenin, another flavone found in parsley, thyme, and peppermint, showed down-modulation of the constitutive expression of NF- $k \mathrm{~B}$ with an decrease in $\mathrm{I} k \mathrm{~B} \alpha$ expression in prostate cancer cells [59]. Chrysin, an active component of Oroxylum indicum, inhibited NF- $k \mathrm{~B}$ activity through the inhibition of $\mathrm{I} k \mathrm{~B} \alpha$ phosphorylation and diminished IL- 8 secretion in human intestinal Caco-2 cells [60].

Baicalein, a component of Scutellaria baicalensis, was found to inhibit inflammation by suppressing LPS-induced degradation of $\mathrm{I} \kappa \mathrm{B} \alpha$ and formation of NF- $\kappa \mathrm{B}-\mathrm{DNA}$ complex. Baicalein also decreased levels of iNOS and the overproduction of NO and superoxide anions caused by LPS [61]. Along with baicalein, wogonin and baicalin which are also the components of Scutellaria baicalensis showed anti-inflammatory activities. Wogonin suppressed IL-1b-induced IL-6 and IL-8 production in ARPE-19 cells. Wogonin also suppressed the NF- $k$ B binding activities in ARPE- 19 cells indicating anti-inflammatory effects of baicalein and wogonin [62]. Baicalin inhibited COX-1 and COX-2 peroxidase and 5-LOX enzyme activities to reduce production of proinflammatory eicosanoids and attenuated edema in an in vivo model of inflammation [63]. The anti-inflammatory activity of baicalin was also found by inhibiting the binding of a number of chemokines such as CXC, IL-8, CC [macrophage inflammatory protein (MIP)- $1 \beta$, monocyte chemotactic protein (MCP)-2], and C [lymphotactin (Ltn)] to human leukocytes which was further associated with a reduced capacity of the chemokines to induce cell migration [64]. Cayaponia tayuya root extract which contains the flavone isovitexin as a bioactive component showed an anti-inflammatory response in models of topical mouse ear edema. The anti-inflammatory activity of $C$. tayuya root extract is most likely due to inhibition of the induction of the enzymes COX-2 and iNOS [65]. Another study showed that isovitexin extracted from Oryza sati$v a$ inhibited the release of TNF- $\alpha$, a proinflammatory cytokine and PGE2 production, upon LPS activation [66].

Flavopiridol, a synthetic flavone closely related to a compound originally isolated from the stem bark of the native Indian plant
Dysoxylum binectariferum, has been found to suppress inflammation, inhibit cyclin-dependent kinases, induce apoptosis, and modulate the immune response. The inhibition of TNF-induced inflammation by flavopiridol was associated with inhibition of NF- $k$ B activation. This effect was mediated through inhibition of IKK, phosphorylation, ubiquitination, and degradation of $\mathrm{I} k \mathrm{~B} \alpha$, and suppression of phosphorylation, acylation, and nuclear translocation of the p65 subunit of NF- $k B$ [67]. However, biochemical analysis of plasma in patients undergoing infusional flavopiridol found a significant induction of IL-6 leading to the appearance of the proinflammatory syndrome [68]. Ochnaflavone exhibits anti-inflammatory activity through the regulation of proinflammatory gene expression in vitro and in vivo. This molecule also exhibits phospholipase A2, COX-2 and 5-LOX inhibitory activity [69]. Suh et al. [70] also showed that LPS-induced iNOS expression is abolished by ochnaflavone in RAW 264.7 cells by blocking the inhibition of transcription factor NF$\kappa \mathrm{B}$ binding activities. These activities of ochnaflavone were found to be associated with the downregulation of IKK activity, thus inhibiting LPS-induced phosphorylation as well as the degradation of $\mathrm{I} k \mathrm{~B} \alpha$.

Regulation of inflammatory pathways by flavonols: Flavonols are a class of flavonoids that have a 3-hydroxyflavone backbone and are present in a wide variety of fruits and vegetables, including onion, kale, broccoli, lettuce, tomato, apple, grape, berries, tea, and red wine. The greener a leaf is, the more flavonols it contains. The major dietary flavonols are quercetin, kaempferol, myricetin, and isorhamnetin. Various studies have shown that flavonols have properties that reduce several diseases, including inflammation and cancer.

In one example, it was reported that the red wine flavonoid quercetin inhibits 12-O-tetradecanoylphorbol-13-acetate (TPA)-induced activation of activator protein- 1 and NF- $k$ B. Quercetin also inhibited the transformation of mouse skin epidermal (JB6 P+) cells [71]. Another major flavonol present in red wine, myricetin (3,3',4',5,5',7-hexahydroxyflavone), inhibited TPA-induced COX-2 expression in JB6 P+ cells by suppressing the activation of NF- $k \mathrm{~B}$ [72]. Muñoz-Espada and Watkins [73] showed that the flavonols cyanidin and kaempferol reduced the level of $\mathrm{PGE}_{2}$ and COX-2 protein in LNCaP cell cultures. They further showed that the reduction of COX-2 by kaempferol and cyanidin may be mediated through the actions of NF- $k$ B and PPAR $\gamma$ as nuclear factors that bind to the COX-2 gene promoter. Isorhamnetin isolated from Smilax bockii warb showed moderate activity in inhibiting TNF$\alpha$-induced NF- $k \mathrm{~B}$ activation with an $\mathrm{IC}_{50}$ value of $166.6 \mu \mathrm{g} / \mathrm{mL}$ [74]. Another study found that isorhamnetin inhibited both NF- $k$ B and STAT- 1 in activated macrophages [75].

Regulation of inflammatory pathways by flavanones: Flavanones are a subgroup of flavonoids with the basic structure 2,3-dihydro-2-phenylchromen-4-one. The major flavanones are hesperetin, naringenin, eriodictyol, and homoeriodictyol, and they play an important role in the inhibition of inflammation and cancer. For instance, naringenin present in orange and grape juice was found to inhibit iNOS protein and NO production through downmodulation of NF- $k \mathrm{~B}$ in activated macrophages [75]. Another compound, poncirin, a flavanone glycoside isolated from the dried immature fruits of Poncirus trifoliata, showed anti-inflammatory effects by inhibiting PGE 2 and IL-6 production. Poncirin also reduced LPS-induced protein levels of iNOS and COX-2 and the DNA binding activity of NF- $k B$ [54]. Hesperetin, another flavanone abundant in citrus fruits, has shown variety of pharmacological properties like antioxidant, cholesterol-lowering, and 
anti-inflammatory properties. In one animal study, hesperetin fed to 6- and 24-month-old rats modulated NF- $k B$ in their kidneys. Interestingly, hesperetin-induced suppression of NF- $k \mathrm{~B}$ was found to occur through four signal transduction pathways: NIK/IKK, extracellular signal-regulated kinase (ERK), p38, and JNK [76]. In an A549 xenograft athymic BALB/c nu/nu mice model, silibinin (an active flavanone of silymarin, milk thistle) treatment decreased the doxorubicin-induced NF- $k$ B DNA binding. Further study to determine the mechanism of action showed that silibinin inhibited the increased translocation of p65 and p50 from cytosol to nucleus caused by doxorubicin. Silibinin also inhibited COX-2, an NF- $k$ B target, in combination with doxorubicin [77]. Another component of milk thistle, taxifolin, also potently inhibited IFN gamma-induced ICAM-1 expression in a reconstructed human skin suggesting therapeutic potential of taxifolin in pathological skin conditions related to increased cell adhesion and inflammation [78]. Psoralea corylifolia, an Ayurvedic medicine in India (Babchi) and BuGuZhi in China, possesses anti-inflammatory, antipyretic, and analgesic activity due to its bakuchiol content. In a study it has been observed that topical administration of this compound effectively inhibited TPA-induced ear edema and myeloperoxidase activity and also reduced the $\mathrm{PGE}_{2}$ content in the arachidonic acid-induced response [79].

Regulation of inflammatory pathways by anthocyanins: Anthocyanins are a subclass of flavonoids synthesized via the phenylpropanoid pathway. Anthocyanins are odorless and nearly flavorless, and they contribute to taste as a moderately stringent sensation. Anthocyanins are found in all tissues of higher plants, including leaves, stems, roots, flowers, and fruits, and they cause a red-blue color. For example, cherries, plums, cabbage, rhubarb, eggplants, almonds, cashews, hazelnuts, pecans, pistachios, peanuts, walnuts, lupine, fava beans, kudzu, psoralea blueberries, bilberries, mulberries and black raspberries are rich sources of anthocyanins. Anthocyanins are derivatives of anthocyanidins, which include pendant sugars. Nearly 600 anthocyanins have been reported. Anthocyanins present in white currant berries showed chemopreventive potential in an experimental model of intestinal tumorigenesis. Treatment in a diet containing $10 \%$ freezedried white currant for 10 weeks fed to multiple intestinal neoplasia (Min) mice showed a reduced number of tumors in the small intestine of study mice, compared with controls. Further study showed that currant reduced nuclear $\beta$-catenin and NF- $k B$ protein levels in the intestinal adenomas [80]. Juices of other berries also induced apoptosis and inhibited inflammation in various cancer cells, including those of the stomach, prostate, intestine, and breast. The apoptosis and anti-inflammatory response are mediated by anthocyanins through inhibition of COX-2 expression and suppression of NF- $k$ B activation in cancer cell lines [81]. Anthocyanins from Oryza sativa have been shown to inhibit the growth and invasion of SKHep-1 cells. These effects were found to be associated with a reduced expression of MMP-9 and urokinase plasminogen activator (u-PA) [82]. The anthocyanins cyanidin 3-rutinoside and cyanidin 3-glucoside (extracted from Morus alba L.) have been reported to exert an inhibitory effect on the migration and invasion of highly metastatic A549 human lung carcinoma cells through reduced expression of MMP-9 and u-PA. It has also been shown that treatment with cyanidin 3-rutinoside and cyanidin 3-glucoside resulted in an inhibition of the activation of c-Jun and NF- $k$ B [83]. Anthocyanins (such as delphinidin, cyanidin, and pelargonidin) found in pomegranates (Punica granatum) possesses strong antioxidant and anti-inflammatory properties. Pomegranate fruit extract (PFE) inhibited UV-B-mediated activation of the NF- $k$ B pathway. Treatment with PFE in normal human epidermal keratinocytes inhibited UV-B-mediated degradation and phosphorylation of $\mathrm{I} k \mathrm{~B} \alpha$ and activation of IKK $\alpha$ which further inhibited nuclear translocation and phosphorylation of NF- $k$ B/p65 at Ser(536) [84].

Regulation of inflammatory pathways by isoflavonoids: Isoflavonoids (or isoflavones) are produced via a branch of the general phenylpropanoid pathway that produces flavonoid compounds in higher plants. Most members of the Fabaceae/Leguminosae (bean) family, including various legumes such as kudzu (Pueraria lobata), lupine (Lupinus spp.), broccoli (Brassica oleracea), cauliflower (Brassica oleracea), barley (Hordeum vulgare), fava beans (Vicia faba), and soy (Glycine max), are the major source of isoflavones. Among these, the soybean is the most common source of isoflavones in human food. The major isoflavones in soybean are genistein and daidzein. Other dietary sources of isoflavones are chick peas (biochanin A), alfalfa (formononetin and coumestrol), and peanuts (genistein). Studies have shown that isoflavones have diverse effects on human and animal health, including inflammation and cancer. Genistein, a major isoflavone, was found to inhibit NF- $k$ B activation during acute lung injury induced by LPS in rats. Intratracheal treatment of rats with LPS $(6 \mathrm{mg} / \mathrm{kg})$ resulted in increased DNA-binding activity of NF- $\kappa$ B in alveolar macrophages and lung tissue. However, 2-h pretreatment with genistein (50 mg/kg, intraperitoneally) inhibited the LPS-induced induction of NF- $k B$ activation and changes in lung injury [85]. Equol, an isoflavonoid, inhibited the LPS-induced activation of NF- $k$ B as well as binding to DNA. A study in RAW 264.7 cells showed that inhibition of NF- $k$ B by equol was mediated through inhibition in degradation of $\mathrm{I} \kappa \mathrm{B} \alpha$ and $\mathrm{I} \kappa \mathrm{B} \beta$ and nuclear translocation of the p65 subunit of NF- $k \mathrm{~B}$ [86]. We found that the isoflavonoid morin, isolated from mulberry figs, almond hulls and old fustic (Chlorophora tinctoria), inhibited NF- $k$ B activation induced by different inducers such as TNF, phorbol 12-myristate 13-acetate, LPS, ceramide, IL- 1 , and $\mathrm{H}_{2} \mathrm{O}_{2}$ in different cancer cells. The suppression of NF- $k$ B by morin was mediated through inhibition of IKK, leading to suppression of phosphorylation and degradation of $\mathrm{I} \kappa \mathrm{B} \alpha$ and consequent nuclear translocation of p65 [87]. In a study of in situ human DeltaF508 cystic fibrosis bronchial tissues, isoflavones showed an anti-inflammatory response. It has been observed that treatment of cystic fibrosis gland cells with the isoflavone genistein resulted in decreased IL-8 production and that genistein reversed the effects of LPS Pseudomonas aeruginosa-induced nuclear translocation of NF- $k \mathrm{~B}$ by increasing $\mathrm{I} \kappa \mathrm{B} \alpha$ protein levels in cystic fibrosis gland cells [88]. The isoflavones daidzein and genistein have also been shown to suppress NF- $k$ B and STAT-1, which are significant transcription factors for iNOS involved in inflammation [75]. Glabridin, a isoflavonoid present in licorice extract, is also known to have anti-inflammatory, antimicrobial, and cardiovascular protective activities. One study showed that glabridin attenuated LPS-induced NO production and NF- $k B$ activation in isolated mouse peritoneal macrophages and RAW 264.7 cells. The inhibition of NF- $k$ B by glabridin in RAW 264.7 cells was mediated through the inhibition of $\mathrm{I} k \mathrm{~B} \alpha$ degradation and p65 nuclear translocation [89]. Irigenin, another isoflavonoid from the rhizomes of Belamcanda chinensis (Iridaceae), was found to have anti-inflammatory effects in RAW 264.7 cells. It has been shown that irigenin inhibited the expression of iNOS and COX-2 proteins. Treatment of the transfectant RAW 264.7 cells with irigenin also reduced the level of NF- $k B$ activity associated with decreased p65 protein levels in the nucleus [90]. Vitexin which is found in caraway (Eleusine indica) inhibits 
inflammation by preventing lung neutrophil recruitment in mice exposed to aerosols of LPS from gram-negative bacteria [91]. Recent studies have shown that tangeretin (5,6,7,8,4'-pentamethoxyflavone), a polymethoxylated flavonoid concentrated in the peel of citrus fruits, exhibits antiproliferative, anti-invasive, antimetastatic, and antioxidant activities. It down-modulated IL1 induced COX-2 expression. Pretreatment of cells with tangeretin inhibited IL- $1 \beta$-induced p38 MAPK, JNK, and AKT phosphorylation and the downstream activation of NF- $k B$ [92]. Since NF- $k B$ is also required for the replication of HIV, it is possible that antiHIV activity associated with 5,3'-dihydroxy-3,6,7,8,4'-pentamethoxyflavone (PMF) is due to suppression of NF-kB [93].

It is very evident from the foregoing discussion, and as also summarized in $\odot$ Table 2 , that the anti-inflammatory activity of flavonoids, in general, is attributed to their ability to inhibit NF- $k$ B activation by a wide variety of inflammatory stimuli. This is brought by inhibiting the phosphorylation of $I k \mathrm{~B} \alpha$, and its subsequent degradation. Phosphorylation of $I k \mathrm{~B} \alpha$ is inhibited by inhibition of IKK activity. However, the pathway through which IKK activity is inhibited has not been delineated unequivocally, in most of the cases. However, the involvement of ROS has been postulated in the case of some of the flavonoids. Once the NF- $k B$ is inhibited, the expression of all the downstream targets genes, such as COX2, MMP-9, ICAM1, iNOS, etc. are brought down. In some instances, in addition to inhibiting the NF- $k$ B pathway, the NRF-2 pathway and its downstream target HO-1 were shown to be activated. The above pathways invariably have been worked out in vitro, but their in vivo validation is lacking.

\section{Role of Flavonoids in Apoptosis, Proliferation, and Angiogenesis}

Apoptosis especially plays a crucial role in the regulation of tissue homeostasis, and an imbalance between cell death and proliferation may result in tumor formation [94]. Tumor cells can break away, leak, or spill from a primary tumor, enter lymphatic and blood vessels, circulate through the bloodstream, and be deposited within normal tissue elsewhere in the body. After metastasis, a new tumor is formed, called a secondary or metastatic tumor, and its cells are like those in the original tumor. In the tumor, new blood vessel formation starts from preexisting vessels in a process called angiogenesis. Metastatic cancer cells exhibit a resistance to apoptosis. NF- $k$ B activation leads to the expression of genes that are involved in the proliferation, survival, angiogenesis, invasion, and metastasis of cancer [95]. Thus, there is growing interest in the potential of flavonoids to modulate NF- $k$ B-regulated gene products and fight cancer; however, it is not yet clear how flavonoid consumption affects the cancer risk in humans. Various in vitro, in vivo, and clinical studies have shown that flavonoids modulate different genes involved in the regulation of apoptosis, proliferation, metastasis and angiogenesis ( $\mathbf{0}$ Fig. 5).

Role of chalcones in apoptosis, proliferation, and angiogenesis: A study on chalcone showed that it inhibits the proliferation of T24 and HT-1376 cells by blocking the cell cycle progression in the G2/M phase through the regulation of p21, p27, cyclin B1, cyclin $\mathrm{A}$, and $\mathrm{Cdc} 2$ proteins and inducing apoptosis through the induction of Bax and Bak, decreasing the levels of Bcl-2 and Bcl-xL, and inducing the release of cytochrome $\mathrm{c}$ and activation of caspase-9 and caspase-3 [49]. The major prenylated chalcone, xanthohumol, found in hops (Humulus), is well-known to exert anticancer effects. In fact, xanthohumol at a concentration of $25 \mu \mathrm{M}$ repressed proliferation and migration and induced apoptosis in two HCC cell lines (HepG2 and Huh7). Xanthohumol also inhibits

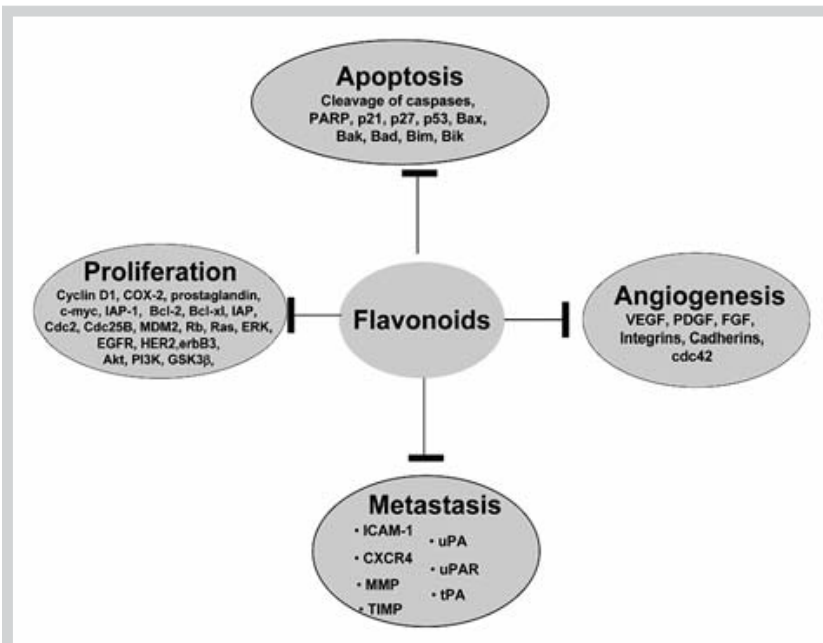

Fig. 5 Molecular targets of flavonoids for inhibition of proliferation, metastasis, and angiogenesis, and induction of apoptosis. VEGF, vascular endothelial growth factor; PDGF, platlets derived growth factor; PARP, poly (ADP-ribose) polymerase; MDM2, murine double minute 2; EGFR, epidermal growth factor receptor; PI3K, phosphoinositide 3-kinases; GSK-3 $\beta$, glycogen synthase kinase-3 $\beta$; ICAM-1, intercellular adhesion molecule-1; CXCR4, CXC chemokine receptor; MMP-9, matrix metallopeptidase-9; TIMP, tissue inhibitor of metalloproteinases.

TNF-induced NF- $k$ B activity and IL-8 expression in both cell lines at even lower concentrations $[96,97]$.

Butein (3,4,2',4'-tetrahydroxychalcone), another chalcone (isolated from stem bark of cashew), exhibits antiproliferative and apoptotic effects against tumor cells through suppression of the STAT3 activation pathway. The suppression of STAT3 was mediated through the inhibition of activation of the upstream kinases c-Src, Janus-like kinase (JAK) 1, and JAK2 [98]. It also inhibited the proliferation of breast cancer cells expressing aromatase. Thus, butein was found to be the strongest aromatase inhibitor among the compounds tested in that study - 2-hydroxychalcone, 2'-hydroxychalcone, 4-hydroxychalcone, 4,2',4'-trihydroxychalcone (isoquiritigenin), and 3,4,2',4'-tetrahydroxychalcone (butein) and its $\mathrm{IC}_{50}$ value was $3.75 \mu \mathrm{M}$ [99].

Isoliquiritigenin, isolated from licorice and shallots, inhibits the proliferation of A549 human non-small cell lung cancer cells. Isoliquiritigenin also induced apoptosis and blocked cell cycle progression in the G1 phase through increased expression of Fas/ FasL, p53, and p21/WAF1 protein [100]. Isoliquiritigenin was also found to inhibit cell cycle progression at the G2/M phase through the enhanced expression of p21(CIP1/WAF1) in lung cancer cells and GADD153 in prostate cancer cells [101]. In MGC-803 cells, isoliquiritigenin treatment showed apoptosis as indicated by the typical morphological and biochemical features of apoptosis including cell shrinkage, chromatin condensation, DNA ladder formation, and the appearance of apoptotic peaks (subG1) [102]. In addition, isoliquiritigenin reduced pulmonary metastasis of mouse renal cell carcinoma without any weight loss or leukocytopenia [103].

The chalcone derivatives xanthoangelol and 4-hydroxyderricin, isolated as main components from the Angelica keiskei Koizumi (Umbelliferae) root, have antitumor and antimetastatic properties to the lung or liver in subcutaneous or intrasplenic LLC-implanted C57BL/6J female mice. 4-Hydroxyderricin at a dose of $50 \mathrm{mg} / \mathrm{kg} \times 2 /$ day orally inhibited tumor growth in subcutaneous 
LLC-implanted mice, inhibited lung metastasis, and prolonged survival time in mice [104]. Xanthoangelol also inhibited tumor growth in LLC-bearing mice as well as lung and liver metastasis and prolonged survival time in carcinectomized mice at a daily dose of $50 \mathrm{mg} / \mathrm{kg}$ [105]. The antitumor and/or antimetastatic activities of xanthoangelol and 4-hydroxyderricin may be due to inhibition of DNA synthesis and of tumor-induced neovascularization through inhibition of the formation of capillary-like tubes by vascular endothelial cells and inhibition of the binding of VEGF to vascular endothelial cells $[104,105]$. In addition, 2'-hydroxy-4'methoxychalcone showed antiangiogenic and antitumor activities in in vitro and in vivo studies. This compound decreased the angiogenesis in chick embryos and mice implanted with murine Lewis lung carcinoma. It has been observed that the antiangiogenic activities of 2'-hydroxy-4'-methoxychalcone might be due to antiproliferative activity under inhibition of COX-2 enzyme [106].

Role of flavones in apoptosis, proliferation, and angiogenesis: Apigenin, a common dietary flavone, has been shown to possess antitumor properties. In one study of human ovarian cancer A2780 cells, apigenin was found to inhibit proliferation and tumorigenesis through Id1 (inhibitor of differentiation or DNA binding protein 1). Apigenin suppressed the expression of Id1 through activating transcription factor 3 (ATF3) [107]. Apigenin also inhibits motility and invasion, disrupts actin cytoskeleton organization, and modulates focal adhesion kinase (FAK)/Src signaling of PC3 cells [108]. In a study of human ovarian cancer A2780 cells, apigenin was found to inhibit the expression of FAK, which plays an important role in the migration and invasion of cancer cells. An in vivo study also showed that apigenin inhibited the spontaneous metastasis of A2780 cells implanted onto the ovary of nude mice [109]. HGF-induced cell motility, scattering, cell migration, and invasion were repressed by apigenin through blocking of Akt phosphorylation but not Met, ERK, and JNK phosphorylation in hepatoma SK-Hep1 cells and lung carcinoma A549 cells [110].

The natural flavone diosmetin which is present in plants belonging to the genus Teucrium (Lamiaceae) and in Portuguese olive leaves along with other fruits and vegetables, was also found to inhibit the proliferation of breast adenocarcinoma MDA-MB 468 , which caused an arrest of the cell cycle at the G1 phase at $10 \mu \mathrm{M}$ [111]. The flavone luteolin present in tea, tomatoes, apples and other fruits and vegetables, has multiple anti-inflammation, antiallergy, and anticancer effects. The anticancer properties of luteolin have been associated with the induction of apoptosis and inhibition of cell proliferation, metastasis, and angiogenesis through suppression of cell survival pathways such as phosphatidylinositol 3'-kinase (PI3K)/Akt, NF- $k \mathrm{~B}$, and XIAP and stimulation of apoptosis pathways, including those that induce the tumor suppressor p53 [112]. Another study showed that the antiproliferative effect of luteolin is associated with the arrest of cells at the G2/M phase regulated through the proteins $\mathrm{Cdc} 2$, cyclin B1, Cdc25C, and p21/cip1 in gastric cancer AGS cells. In these cells, luteolin also induced apoptosis through increasing the levels of proapoptotic proteins, including caspases-3, -6, and -9, Bax, and p53 and decreasing levels of the antiapoptotic protein Bcl-2 [113]. An in vivo study of murine xenografts showed that luteolin inhibited tumor growth and angiogenesis induced by VEGF. Luteolin inhibited VEGF-induced PI3K and abolished activation of Akt in human umbilical vein endothelial cells [114]. Another study showed that luteolin inhibits the invasion of prostate cancer PC3 cells through E-cadherin. The luteolin-induced expres- sion of E-cadherin was mediated through the Akt/mdm2 pathway. In vivo experiments also showed that luteolin inhibited spontaneous lung metastasis of PC3 cells implanted into nude mice [115].

Protoapigenone, a novel flavonoid isolated from the whole plant Thelypteris torresiana, was found to have cytotoxic effects on ovarian cancer MDAH-2774 and SKOV3 cells [116]. Protoapigenone arrested MDAH-2774 and SKOV3 cells at the S and G2/M phases via decreasing the expression of p-Cdk2, Cdk2, p-cyclin $\mathrm{B} 1$, and cyclin B1, as well as increasing the expression of inactive p-Cdc25C and inducing apoptosis through decreasing protein levels of Bcl-xL and Bcl-2 and increasing levels of cleaved poly(ADPribose) polymerase (PARP) by activating caspase-3. In one in vivo study in nude mice, protoapigenone treatment significantly suppressed tumor growth without major side effects [116].

Nobiletin, an effective component of citrus fruit, showed antiproliferative activity on lung cancer cells both in vitro and in vivo. Nobiletin-induced cell p53-mediated cycle arrest at the G2/M phase and further apoptosis via modulated the Bax: Bcl-2 protein ratio in A549 cells. Nobiletin had an overt inhibitory effect on tumor growth in the nude mice model as observed in vivo [117]. Nobiletin inhibits TPA-stimulated tumor metastasis by inhibiting the phosphorylation of MEK and thereby suppressing MMP expression in human fibrosarcoma HT-1080 cells [118]. The decrease in MEK activity caused by nobiletin was found to inhibit the phosphorylation of ERK, a downstream signaling factor for MEK [119]. Another citrus component, tangeretin, also inhibits proliferation of human breast cancer cell lines MDA-MB-435 and MCF-7 and human colon cancer line HT-29 up to $80 \%$ over the course of 4 days, by cell cycle arrest without inducing apoptosis [120]. An in vitro study showed that tangeretin inhibits the invasion of MO4 cells into embryonic chick heart fragments. That study showed a decrease in ATP content in MO4 cells after tangeretin treatment; thus, it was deduced that this flavonoid inhibits a number of intracellular processes, which leads to an inhibition of cell motility and, hence, of invasion [121]. Zapotin (5,6,2',6'tetramethoxyflavone), found in the tropical fruit zapote blanco (Casimiroa edulis), showed a marked suppression of cell proliferation in the HT-29 cells through accumulation of cells in the G2/M phase, with a concomitant decrease of cells in the G0/G1 phase. It also inhibits the generation of aberrant crypt foci in mice [122].

Fisetin and gossypin regulate the proteins involved in antiapoptosis (cIAP-1/2, Bcl-2, Bcl-xL, XIAP, survivin, and TRAF1), proliferation (cyclin D1, c-Myc, and COX-2), invasion (ICAM-1 and MMP-9), and angiogenesis (VEGF) and exhibits anticancer effects [55]. In a study it has been shown that acacetin (5,7-dihydrocy4'-methoxyflavone) possesses the ability to inhibit cell proliferation and induce apoptosis in human gastric carcinoma AGS cells. The induction of apoptosis by acacetin was mediated through the mitochondrial cell death pathway. Acacetin-induced cell death was characterized by a loss of mitochondrial transmembrane potential, stimulation of ROS, release of mitochondrial cytochrome c into the cytosol, induction of procaspases- 9 and -3 , and subsequently DNA fragmentation [123]. Acacetin also showed strong cell growth inhibition by cell cycle arrest at the G2/M phase accompanied by cell death in human prostate cancer LNCaP and DU145 cells. G2/M arrest was associated with a decrease in Cdc25C, Cdc2/p34, and cyclin B1, which were more prominent in LNCaP than in DU145 cells [124].

Other flavones, 7-hydroxyflavanone, 5,6,7-trihydroxyflavanone, and 4',5,7-trihydroxyflavanone, were found to exert an inhibi- 
tory effect on the invasion and migration of SCC- 4 cells. Treatment of flavones decreased the expression of MMP-2 and u-PA together with altered expression levels of their endogenous inhibitors, such as the tissue inhibitor of metalloproteinase-2 (TIMP-2) and plasminogen activator inhibitor-1 (PAI-1). An in vivo chorioallantoic membrane (CAM) intravasation also revealed the antimetastatic effect of flavones [125]. In combination, tangeritin enhanced the ability of cisplatin to inhibit the proliferation and apoptosis of A2780/CP70 and 2008/C13 cisplatin-resistant human ovarian cancer cells. Tangeritin activates apoptosis via the caspase cascade and by arresting the cell cycle at the $\mathrm{G} 2 / \mathrm{M}$ phase. Upon tangeretin-cisplatin treatment, phospho-Akt, NF- $k B$, phospho-GSK-3 $\beta$, and phospho-BAD were downregulated [126]. Baicalein inhibits the proliferation of cells by blocking cell cycle progression in the $\mathrm{S} / \mathrm{G} 2 / \mathrm{M}$ phase and inhibits cyclin D1, p42/44 MAPK, and Akt phosphorylation without changes in other cell cycle regulatory proteins [127]. In contrast, baicalein, chrysin, and scutellarein inhibited the proliferation of MDA-MB-468 cells to a lesser extent than sinensetin and genkwanin [128]. Baicalin inhibited cell proliferation of human lung carcinoma A549 and mouse Lewis lung cancer. An in vivo study showed that baicalin suppressed tumor growth and prolonged survival in $\mathrm{C} 57 \mathrm{BL} / 6$ mice bearing LLC tumor and nude mice bearing A549 carcinoma without systemic toxicity [129].

Flavopiridol which is in clinical phase I/II trial inhibits the growth of MDA-MB-435 breast cancer cells, induces apoptosis, regulates the expression of genes, and inhibits invasion and metastasis of breast cancer cells. Induction of apoptosis by flavopiridol was measured by DNA laddering, PARP, and CPP32 cleavages. It also showed modest upregulation of Bax and downregulation of Bcl2 , as well as significant downregulation of c-erbB-2 in flavopiridol-treated cells. Flavopiridol inhibits cell invasion by inhibiting the secretion of erbB-2, MMP-2 and 9 in the breast cancer cells [130]. Ochnaflavone, a biflavonoid present in the human diet, is known to inhibit angiotensin II-induced hypertrophy and serum-induced smooth muscle cell proliferation. Further study showed that its inhibitory effects are associated with reduced ERK1/2 activity and G1 cell cycle arrest. The cell cycle block was found to be mediated through induced downregulation of cyclins and CDKs and upregulation of the CDK inhibitor p21(waf1) expression. It also showed antimetastatic properties by the inhibition of MMP-9 gene expression in human aortic smooth muscle cells [70].

Role of flavonols in apoptosis, proliferation, and angiogenesis: Kaempferol, a natural flavonoid present in many fruits and vegetables like spinach, tea, onions, curly kale, leeks, broccoli, and blueberries, has been found to only slightly induce cytotoxicity in OVCAR-3 and A2780/CP70 human ovarian cancer cells but to inhibit angiogenesis, VEGF expression, and Akt phosphorylation. HIF-1 $\alpha$, a regulator of VEGF, is also downregulated by kaempferol in ovarian cancer cell lines [131]. In the human HCT116 colon cancer cell line, kaempferol induced p53-dependent growth inhibition and apoptosis. It induced ATM and H2AX phosphorylation and cytochrome $c$ release from mitochondria and activated caspase-3 cleavage [132]. Quercetin, a ubiquitous bioactive flavonol present in scallions, tea, tomatoes, alfalfa seeds, and apples, inhibits cell proliferation and induces cell cycle arrest and apoptosis in different cancer cell types. Quercetin induced apoptosis promoted by the activation of caspases-3, -8 , and -9 in MDA-MB-231 cells [133]. Another study showed that, instead of cleavage of caspases, quercetin also decreased the levels of survivin and Bcl-2 protein expression in HepG2 cells and concurrently increased the levels of p53 [134]. Quercetin induced cell cycle arrest at G2/ M of SW480 cells in a process mediated through cyclin D1 and survivin gene regulation [135]. Beside apoptotic and antiproliferative effects, quercetin was found to inhibit adhesion and migration and invasion of HeLa cells [136]. Quercetin sensitized TNFrelated apoptosis-inducing ligand (TRAIL)-mediated apoptosis in U87-MG, U251, A172, and LN229 glioma cells. The TRAIL-induced enhanced apoptosis by quercetin was mediated through reduction of the survivin protein [137]. In a study on glioma cells, quercetin caused a rapid reduction in phosphorylation of ERK and Akt. Quercetin-induced depolarization of the mitochondrial membrane is thought to lead to a decrease in expression of antiapoptotic proteins and caspase activation and, finally, to apoptosis [138]. Quercetin also inhibits cell proliferation in ER-positive MCF-7 and T47D cells. It has been found that quercetin stimulates $\mathrm{ER} \beta$ responses more than $\mathrm{ER} \alpha$, the receptor possibly involved in adverse cell proliferative effects [139].

In addition to quercetin, isoquercetin and rutin also affect the proliferation of $\mathrm{Gbm}$ cells. Isoquercetin did not show apoptosis, but inhibition of cell proliferation was found to be associated with a reduction in cyclin D1 levels and an increase in p27 levels [140]. Rutin was shown to induce apoptosis in leukemia WEHI-3 cells implanted in BALB/c mice, which showed a decreased percentage of the Mac-3 marker after rutin treatment, indicating that the differentiation of the precursor of macrophage and $\mathrm{T}$ cells was inhibited [141]. Pachypodol (5,4'-dihydroxy-3,7,3'-trimethoxyflavone), a flavonol isolated from the leaves of Calycopteris floribunda, has been found to cytotoxic as evaluated by the Promega's cell titer 96 nonradioactive cell proliferation assay using CaCo-2 colon cancer cells [142].

Resveratrol is also known to inhibit proliferation and induce apoptosis in tumor cells. In one study, resveratrol was tested in mouse xenograft models of human neuroblastoma and in vitro using human cell lines. Results of this study showed that resveratrol inhibited the outgrowth of tumors and decreased tumor cell viability in vitro by inhibiting cell proliferation and inducing apoptosis. Resveratrol caused depolarization of mitochondrial membrane potential, release of cytochrome $\mathrm{c}$ and Smac/Diablo from the mitochondria, and subsequently activation of caspases- 9 and -3 [143]. In vitro results also showed that resveratrol inhibits survival and induces apoptosis in MOLT-4 acute lymphoblastic leukemia cells through modulating signaling pathway Notch and its downstream effector. This flavonol induces levels of the proapoptotic protein p53 and its effectors p21waf and Bax, inhibits the PI3K/Akt pathway, and activates Gsk-3 $\beta$ [144]. The antiproliferative activity of resveratrol is due to induced cell cycle arrest and finally apoptosis $[145,146]$. The cell cycle arrest by resveratrol of SPC-A-1/CDDP cells was found between the G0/G1 and S phase or at the G2/M phase. It showed antitumour effects in nude mice that had been implanted with SPC-A-1/CDDP cells [147]. Resveratrol triggered c-Jun- $\mathrm{NH}_{2}$-terminal-kinase activation, followed by the activation of intrinsic and extrinsic caspase pathways in Waldenström's macroglobulinemia cells [146].

It has been found that grape polyphenols at physiologically relevant concentrations are more effective than individual compounds at inhibition of $\mathrm{ERa}(-), \mathrm{ERb}(+) \mathrm{MDA}-\mathrm{MB}-231$ breast cancer cell proliferation, cell cycle progression, and primary mammary tumor growth [148]. It has also been found that combined grape polyphenols induced apoptosis, inhibition of cell proliferation, cell cycle progression, and cell migration more effectively than individual resveratrol, quercetin, or catechin in metastatic ER(-) MDA-MB-435 cells [149]. Myricetin exhibited a reduction 
of cell vitality and induction of apoptosis via the caspase-dependent pathway in DU-145 cells [150]. A clinical study showed that there is a strong association between the intake of flavonoids and colorectal cancer incidence. In 71976 women from the Nurses' Health Study and 35425 men from the Health Professionals Study, results showed that the intake of flavonols, including quercetin, myricetin, and kaempferol, was related to a lower risk of colorectal cancer [151].

Role of flavanones in apoptosis, proliferation, and angiogenesis: Flavonones have been found to inhibit TPA-induced proliferation of NIH3T3 cells. The structurally related 2'-hydroxyflavanone, 4'hydroxyflavanone, and 6-hydroxyflavanone showed inhibition of TPA-stimulated MAPK phosphorylation, COX-2, ODC, c-Jun protein expressions and $\mathrm{PGE}_{2}$ production. Thus, the blocking TPA-induced intracellular signaling responses might be involved in the antipromotive mechanism of flavanones [152]. Despite an influence on cell viability, flavanone and 2'-hydroxyflavanone markedly inhibited the invasion, motility, and cell-matrix adhesion of A549 cells. This was associated with a reduced expression of MMP-2 and u-PA in A549 cells. The flavanone and 2'-hydroxyflavanone also potently attenuated the phosphorylation of ERK $1 / 2$ and p38MAPK, as well as the activation of NF- $k$ B and AP-1 [153]. The flavanone naringenin was shown to exhibit antimitogenic effects by modulating ER $\alpha$-mediated rapid signaling. Naringenin induced ER $\alpha$ activities in the human cervix epitheloid carcinoma cell line (HeLa) devoid of any estrogen receptors and acted as an E2 mimetic on ER $\alpha$ transcriptional activity, whereas it impaired the activation of rapid signaling pathways committed to E2-induced proliferation [154]. Naringenin decreased the binding of E2 to $\mathrm{ER} \alpha$ without impairing the estrogen response element (ERE). Naringenin also prevented E2-induced ERK1/2 and Akt activation and induced the activation of $\mathrm{p} 38$, the proapoptotic member of the MAPK family. As a consequence, naringenin stimulation impeded the E2-induced transcription of cyclin D1 promoter and reverted E2-induced cell proliferation, driving cancer cells to apoptosis [155]. Naringenin-induced apoptosis has been demonstrated by the activation of p38/MAPK leading to the proapoptotic caspase-3 activation and to the PARP cleavage in cancer cell lines [156].

Silymarin and silibinin $(50-100 \mu \mathrm{g} / \mathrm{mL})$ inhibited cell proliferation, apoptosis, and cell cycle arrest. G1 arrest was found to be associated with regulation of cyclin D1, cyclin D3, cyclin E, cyclindependent kinase (CDK)4, CDK6, and CDK2 protein CDK inhibitors (CDKIs) Kip1/p27 and Cip1/p21. Silibinin and silymarin also induced cell cycle arrest at the G2/M phase, and this was associated with decreased levels of cyclin B1, cyclin A, pCdc2 (Tyr15), Cdc2, Cdc25B, and Cdc25C [157]. Taxifolin induced apoptosis by affecting mitochondrial membrane potential. A study suggested that the 2,3 double bond/3-hydroxy group of this flavonone in conjugation with the 4-oxo function on the ring seem to favor the interaction of these compounds with the mitochondrial membrane, decreasing its fluidity by either inhibiting the respiratory chain of mitochondria or causing uncoupling [158]. The synthetic flavanone derivative 4 '-chloroflavanone was found to inhibit cell proliferation through $\mathrm{G} 1 / \mathrm{S}$ phase disruption and to induce apoptosis in both MCF-7 and MDA-MB-453 cells. The cell cycle arrest by 4 '-chloroflavanone was associated with decreased CDK4 and cyclin D and with increased p21/Cip1 expression. The activation of p53 also played a role in 4'-chloroflavanone-induced cell cycle arrest of human breast cancer cells. The apoptosis induced by 4 '-chloroflavanone was due to increased cytochrome c without any change in the expression of Bcl-2 and Bax [159].
Another flavanone, the 2',5,7-trihydroxy-4',5'-(2,2-dimethylchromeno)-8-(3-hydroxy-3-methylbutyl) derivative, isolated from the root bark of Cudrania tricuspidata, was found to cause apoptotic cell death of human leukemia U937 cells. Treatment with this compound in human U937 cancer cells inhibited the activity of topoisomerase I and caused growth inhibition of cells. It induced apoptosis as characterized by cleavage of PARP and procaspase-3 [160]. Another synthesized flavanone derivative, ( \pm )-(3aRS,4SR)-2-(2-chloro-4-methyl- sulfonylphenyl)-4'-chloro3a,4-diethoxyflavane[4,3-d]- $\Delta-1,2,3$-thiadiazoline, was shown to have antileukemic activity. It inhibited the proliferation of leukemic cells and induced apoptosis by inducing procaspase- 9 and procaspase-3 cleavage, XIAP and Bcl-xL downregulation, and PARP degradation and by reducing the phosphorylation of ERK1/2 and increasing the phosphorylation of Jun N-terminal kinase [161].

Role of anthocyanins in apoptosis, proliferation, and angiogenesis: The widespread consumption of diets rich in flavonoids including anthocyanins contributes to the prevention of cancer. Animal studies have shown that grape juice, which contains anthocyanin, inhibited mammary adenocarcinoma multiplicity compared with that in controls through the inhibition of DNA synthesis of rat mammary adenocarcinoma [162]. Recently, it was reported that anthocyanin-rich red grape extract containing oenocyanin interferes with intestinal adenoma development in the $\mathrm{Apc}(\mathrm{Min})$ mouse. The development of adenoma was found to be reduced by oenocyanin-induced modulation of Akt in small intestinal adenomas [163]. Cranberry extract, which contains both anthocyanins and the flavonol glycosides proanthocyanidins, have synergistic or additive antiproliferative interactions. Treatment with cranberry extracts in human oral (KB, CAL27), colon (HT-29, HCT116, SW480, SW620), and prostate (RWPE-1, RWPE-2, 22Rv1) cancer cell lines showed inhibition of proliferation [164]. Anthocyanin-rich extracts from berries and grapes and several pure anthocyanins and anthocyanidins have exhibited proapoptotic effects in multiple cell types in vitro [165-168]. Prodelphinidin B2 3'-O-gallate, a proanthocyanidin gallate isolated from green tea leaves, also has antiproliferative activity in human non-small cell lung cancer A549 cells. Prodelphinidin B2 3'-O-gallate blocked cell cycle progression in the G0/G1 phase and effectively induced apoptosis of A549 cells [169]. Anthocyanidins, the aglycones of anthocyanins, have also been shown to have inhibitory effects on human cancer cell proliferation. The anthocyanidins - cyanidin, delphinidin, pelargonidin, petunidin, and malvidin - inhibited proliferation of human cancer cell lines AGS (stomach), HCT-116 (colon), MCF-7 (breast), NCI H460 (lung), and SF-268 (central nervous system) [170]. Malvidin exhibited a potent antiproliferative effect on AGS cells. The malvidin-induced inhibition of proliferation was accompanied by the arrest of AGS cells at the G0/G1 phase. The occurrence of apoptosis induced by malvidin was confirmed by morphological and biochemical features, including apoptotic body formation, loss of mitochondrial membrane potential, elevation of the Bax: Bcl-2 ratio, caspase 3 activation, and PARP proteolysis [171]. The anthocyanins present in black raspberries contribute to the chemopreventive activity in vivo. Anthocyanin treatment in F344 rats was effective in reducing NMBA-induced tumorigenesis in the esophagus [172].

Delphinidin, another anthocyanin, showed G2/M phase cell cycle arrest, apoptosis, and inhibition of NF- $k$ B signaling in 22Rnu1 cells. Delphinidin treatment of human prostate cancer LNCaP, C4-2, 22Rnu1, and PC3 cells resulted in a dose-dependent inhibi- 
tion of cell growth without showing any substantial effect on normal human prostate epithelial cells. The induction of apoptosis by delphinidin was mediated via activation of caspases [173]. Delphinidin also inhibited VEGF-stimulated human umbilical endothelial cell migration and proliferation and neovascularisation in vivo in a chorioallantoic membrane model [174]. Anthocyanins inhibit metastasis through regulation of MMP-2 and MMP-9, and it also modulates the expression levels of Ras, PI3K, phospho-Akt, and NF- $k$ B as studied in B16-F1 cells [175]. Peonidin 3-glucoside and cyanidin 3-glucoside, major anthocyanins extracted from black rice, also inhibited invasion and motility of SKHep-1 cells through the mechanism of MMP-9u-PA inhibition [82].

Role of isoflavonoids in apoptosis, proliferation, and angiogenesis: Isoflavonoids, flavonoids, and lignans are natural estrogenic compounds derived from soy, tea, fruits, and vegetables, and they have been proposed as chemopreventive agents. It has been known that consumption of a plant-based diet can prevent the development and progression of chronic diseases and also extensive neovascularization of tumor cells. In an epidemiological study it has been observed that the urine of healthy human subjects consuming a plant-based diet had a high content of the isoflavonoid genistein in the micromolar range, which is 30 -fold higher than that of subjects consuming a traditional Western diet. Furthermore, it has been observed that genistein inhibited endothelial cell proliferation and in vitro angiogenesis [176]. Because many Western diseases are hormone-dependent cancers, a vegetarian or semivegetarian diet containing many fruits and vegetables may alter hormone production, metabolism, or action at the cellular level. Soybean products (mainly isoflavonoids but also lignans), as well as whole grain cereals, seeds, and probably berries and nuts (mainly lignans) inhibit growth factor action, malignant cell proliferation, differentiation, and angiogenesis, making them strong candidates for a role as natural cancer protective compounds.

Studies have shown that soy protein preparations containing isoflavonoid conjugates have chemopreventive activity. Rats treated neonatally or prepuberally with genistein have a longer latency and a reduced number of 7,12-dimethylbenz[a]anthracene-induced mammary tumors. Genistein was found to inhibit the rapid proliferation and differentiation of the mammary gland by the inhibition of estrogenic activity [177]. Besides genistein, other isoflavonoids, such as daidzein, biochanin A, formononetin, and equol, also inhibted the proliferation of estrogen receptor ERpositive MCF-7 cells induced by synthetic chemicals 1 -(o-chlorophenyl)-1-( $p$-chlorophenyl)-2,2,2-trichloroethane (o,p'-DDT), 4nonylphenol (4-NP), and 5-octylphenol (5-OP). Among these isoflavonoids, genistein was the most potent inhibitor of MCF-7 cell proliferation [178]. Jung et al. [179] showed that tectorigenin and tectoridin isolated from the rhizomes of Belamcanda chinensis (Iridaceae) inhibited angiogenesis in both in vitro and in vivo models. They observed in a chorioallantoic membrane assay that tectorigenin and tectoridin decreased both angiogenesis of chick embryos and vessel formation in the mouse Matrigel plug assay. Along with these properties, tectorigenin also exhibited strong antiproliferative activity in mice implanted with murine Lewis lung carcinoma. Pterocarpans, natural isoflavonoids, have received considerable interest because of their medicinal properties. Erybraedin C and bitucarpin A are two recently discovered structurally related pterocarpans that show antiproliferative and apoptosis-inducing mechanisms on human adenocarcinoma cell lines LoVo and HT29. Erybraedin C similarly affected the survival of HT29 (MMR +/+, p53 -/-, and Bcl-2 +/+) and LoVo (MMR -/-, p53 +/+, and Bcl-2 -/-) cells, and bitucarpin A affected cell cycle progression on both cell lines, inducing a transient block in G0/G1 and finally inducing apoptosis [180]. Vitexin, an isoflavonoid, showed antitumor effects and cytotoxic activity exerted through a proapoptotic process, which is mediated by a decreased Bcl-2/Bax ratio and activation of caspases [115]. It also diminished the hypoxia-inducible genes such as VEGF, smad3, aldolase A, enolase 1, and collagen type III in the PC12 cells which indicates its antimetastatic potential [181]. Vitexicarpin, a flavonoid from the fruits of Vitex rotundifolia, inhibited T-lymphocyte proliferation as well as B-lymphocyte proliferation at $>0.1$ microM. Vitexicarpin also inhibited the growth of certain cancer cell lines, EL-4 and P815.9 [182]. Morin inhibited the proliferation of cancer cells by inhibiting the gene products IAP-1, IAP-2, XIAP, Bcl-XL, survivin, cyclin D1, and COX-2 and invasion by inhibiting MMP-9 [87].

Considerable evidence has shown that increased consumption of soy and soy isoflavones is associated with a reduced risk for cancer. In a study it has been reported that glycitein, a component of soy, significantly inhibited cellular proliferation of prostate cancer RWPE-1 cells [183]. In the same cancer cells, Clubbs and Bomser [184] showed that glycitein activates ERK1/2, and decreased RWPE-1 cell proliferation. Glycitein-induced ERK1/2 activation was found to be dependent, in part, on tyrosine kinase activity associated with VEGFR. Targeretin has been shown to induce G1 cell cycle arrest in colorectal cancer cells through upregulation of p21, p27 and p53 [185]. Numerous reports have previously shown that the compound isolated from the Gardenia species, 5,3'-dihydroxy-3,6,7,8,4' pentamethoxyflavone, is cytotoxic to various tumor cells $[186,187]$. Thus, these isoflavonoids may act as anticancer agents and could enhance the apoptosis induced by different chemotherapeutic agents.

Flavonoids inhibit cell proliferation and induce apoptosis, in general, through up-modulation of p53 and its regulated gene products (CDK inhibitors), p21/cip1/WAF and p27/Kip1, and downmodulation of cyclin D1, cyclin A, cyclin B1, cdc25C, and cdc2. Consequently, the cell cycle is arrested at the G2/M boundary, and apoptosis is induced by the induction of Bax and Bak, down-moduation of $\mathrm{Bcl}-2$ and $\mathrm{Bcl}-\mathrm{xL}$, the release of cytochrome $C$ and activation of caspases- 9 and -3 . In addition to this, the apoptosis induced by 4 '-chloroflavanone is due to increased cytochrome c release, without any change in the expression of Bcl-2 and Bax. Resveratrol (a flavonol) involves the activation of the mitochondrial pathway, release of cytochrome c and Smac/Diablo from the mitochondria, and subsequently activation of caspases-9 and -3. Resveratrol further inhibits survival, and induces apoptosis through modulating the signaling pathway of Notch and its downstream effectors. The apoptotic pathway is further accentuated by inhibition of the NF-kB-dependent survival pathway. A chalcone (butein) exhibits antiproliferative and apoptotic effects against tumor cells through suppression of the STAT3 activation pathway, which is mediated through the inhibition of the upstream kinases c-Src, Janus kinase (JAK)1 and 2. Some flavonoids inhibit proliferation of breast cancer cells by inhibiting E2dependent proliferation and subsequently driving cancer cells to apoptosis. In some other cases (as in the case of quercetin), involvement of TRAIL-mediated apoptosis through DR 4/5, and reduction in the expression of survivin protein have been shown. The inhibition of angiogenesis by flavonoids proceeds primarily through down-modulation of VEGF expression.

Regulation of inflammatory cytokines and chemokines by flavonoids: Cytokines and chemokines have been postulated to play 
an important role in the maintenance of cell homeostasis and the development of cancers. Therefore, excess production of cytokines and chemokines can be minimized by various flavonoids. Xanthohumol has been shown to repress interleukin-8 expression and proliferation and migration of hepatocellular carcinoma [188]. Amentoflavone, a biflavonoid from Biophytum sensitivum, inhibits proinflammatory cytokine (IL-1beta, IL-6, GM-CSF and TNF-alpha) production in B16F-10 cells and peritoneal macrophages [189]. It also induces apoptosis and inhibits NO production in B16F-10 cells. Ashwagandha (Withania somnifera) treatment in prostate cancer cells downregulated the gene and protein expression of proinflammatory cytokines IL-6, IL-1beta, chemokine IL-8, Hsp70 and STAT-2 and prevented prostate cancer progression [190]. The elevated levels of TNF-alpha in LPS- and Con-A stimulated BALB/c mice were found to be lowered by pretreatment with rutin. Rutin also inhibits nitrite production by activated macrophages in vitro to the normal level [191].

Kaempferol and quercetin activate an immune response in the prostate cancer cells by stimulating GM-CSF production. The stimulated GM-CSF production involves PLC, PKC, and MEK1/2 activation. This GM-CSF production in turn could result in the recruitment of DCs to the tumor site [192]. Flavonoids, kaempferol, quercetin, fisetin, and chrysin have also been shown to block the TNF-alpha induced IL-8 promoter activation and gene expression in HEK 293 cells [193]. Kaempferol suppressed the expression of proinflammatory cytokine interleukin- 6 and chemokines interleukin-8, monocyte chemoattractant protein-1, and regulated, on activation, normal T-cell expression and secretion. Kaempferol inhibited glioma cell migration in a ROS-dependent manner [194]. Flavonoids not only suppress cytokines production, but also inhibit cytokines regulated gene products. A flavonoid, baicalein, inhibits the protein phosphorylation such as that of Jak, STAT3, MAPK, and Akt induced by IL-6 [195]. Silibinin also strongly decreased cytokine mixture-induced phosphorylation of ERK1/2 but only marginally affected JNK1/2 phosphorylation silibinin and downregulated iNOS expression in lung cancer cells [196]. Treatment of hemopoietic cells from human and mouse origin with kaempferol prevents the IL-4-induced phosphorylation of JAK1 and JAK3. It also blocked the in vitro phosphorylation activity of JAK3 without affecting JAK1, suggesting that it specifically targeted JAK3 activity [197].

\section{Flavonoids as a kinase inhibitor via direct binding}

Protein kinases, which phosphorylate a specific substrate, play crucial roles in the regulation of multiple cell signaling pathways and cellular functions. However, deregulation of protein kinases under certain pathological conditions, leads to perturbation of protein kinase-mediated cell signaling pathways and results in various disorders including inflammation and cancer [198]. Because of the involvement of these processes in tumor cell proliferation and survival, regulation of protein kinases would be a promising strategy for the prevention and treatment of cancer [199-201]. It is evident that natural compounds have a great potential in the regulation of multiple cellular signaling pathways and cancer prevention and treatment.

Flavonoids are one of the biggest families of natural products and have been proposed to exert beneficial effects in a multitude of diseases, including cancer. It has been shown that they regulate various cells signaling pathways. Recent studies have suggested that the cellular effects of flavonoids may be mediated by their interactions with specific proteins central to intracellular signaling cascades [202-204]. Studies on the functional activity of fla- vonoids showed that it may interact selectively at different components of a number of protein products including kinases. Interaction or direct binding of flavonoids with kinases such as phosphoinositide 3-kinase (PI3K) [205,206], Akt/protein kinase B (Akt/PKB) [207], protein kinase C (PKC) [205, 208], and mitogenactivated protein kinase (MAPKs) [209] may alter their phosphorylation state to regulate multiple cell signaling pathways (० Fig. 6).

It is known that JAK kinase, one of the non-receptor tyrosine protein kinases, is required for the tyrosine phosphorylation STAT3. The flavonol myricetin is found to bind with JAK1 with rapid formation of the JAK1-myricetin complex. When it is compared with piceatannol, which is a specific inhibitor for JAK1, it slowly reacts with JAK1 [210]. Other than JAK kinase, it also binds to Akt, MEK1, Fyn, MKK4 and PI3K. The results of ex vivo and in vitro binding data showed that myricetin bound directly to the ATPbinding site of Akt with higher binding affinity $\left(K_{\mathrm{d}}=0.26 \mu \mathrm{M}\right)$ [210]. The direct binding of MEK1 was revealed by an ex vivo binding assay and it was found that binding was distinct from the ATP-binding site [72]. However, it directly binds to the ATPbinding site of Fyn [211]. The binding of Fyn was found to be associated with the formation of hydrogen bonds with the backbone of the hinge region of Fyn. As we know, Fyn is a ubiquitously expressed member of the Src family of non-receptor tyrosine kinases that is involved in transmitting signals from various cell surface receptors to cytoplasmic signal transduction cascades. Myricetin also binds to the ATP-binding site of MKK4 as revealed by ex vivo and in vitro binding data [212]. The docking data revealed that myricetin fits easily onto the ATP-binding site of MKK4, located between the $\mathrm{N}$ - and C-lobes of the kinase domain. Like Fyn, myricetin forms hydrogen bonds with the backbone of the hinge region in MKK4. The direct binding of myrecetin with $\mathrm{PI} 3 \mathrm{Kr}$ revealed that it fits into the ATP-binding pocket with a $K_{\mathrm{d}}$ of $0.17 \mu \mathrm{M}$, which is slightly lower than that of quercetin as shown by X-ray crystallography.

Tea flavonoid epigallocatechin gallate (EGCG) also has direct binding properties to kinases. An in vitro protein binding assay revealed that it bound directly to Fyn $\left(K_{d}=0.367 \mu \mathrm{M}\right)$ of the GST-Fyn-SH2 domain but not the GST-Fyn-SH3 domain, which leads to inhibition of its kinase activity [213]. This binding of Fyn by EGCG could inhibit the phosphorylation of EGF-induced p38, activating transcription factor-2 (ATF-2) and STAT1 with attenuated cell transformation. Another flavonol, quercetin, is found to bind directly with Raf1 and MEK1 as observed in ex vivo and in vitro studies. Further study showed that quercetin has a stronger kinase inhibitory activity on MEK1 than Raf1 [71]. Interestingly, quercetin could be docked to the pocket separate from but adjacent to the ATP-binding site of MEK1. However, MEK1 inhibition by resveratrol and kaempferol was found to be weaker than that of quercetin. Although the binding model of resveratrol appears similar to that of quercetin. However, the lack of the hydroxy group at the 3' position of resveratrol would result in the failure of the formation of the hydrogen bond between resveratrol and the backbone amide group of Ser212 [71]. The direct binding of kinase MEK1 was also observed with quercetin. The $\mathrm{X}$-ray crystallographic structure showed that quercetin fits into the ATP-binding site of PI3Kr with a $K_{d}$ value of $0.28 \mu \mathrm{M}$, which is slightly higher than that of myricetin [214]. Isoflavonoid equol bound directly to MEK1 without competing with ATP as observed by pulldown assay. Modeling data further suggest that equol is docked to a pocket separate from but adjacent to the ATP-binding site [215]. 


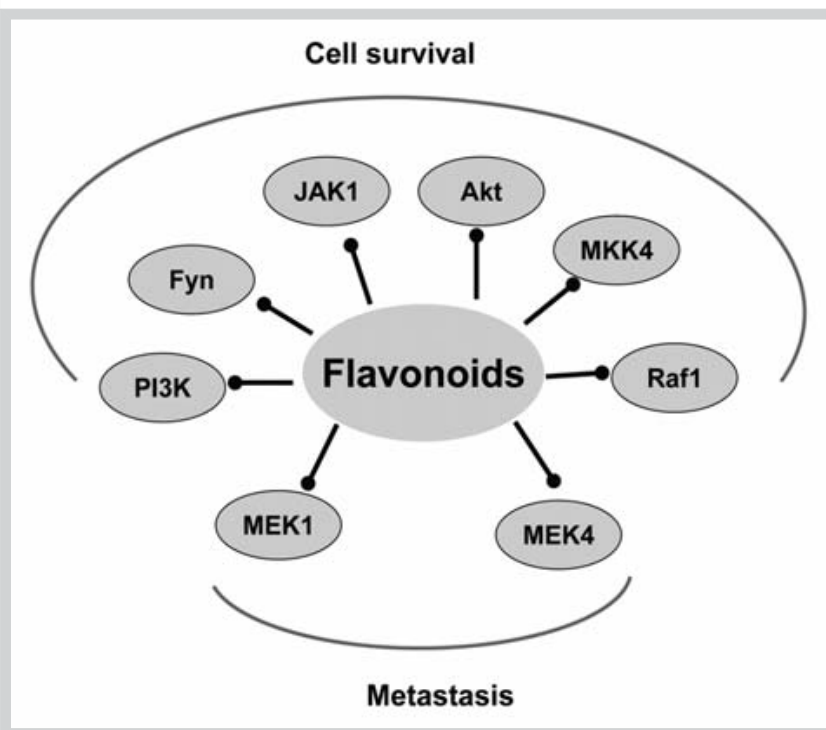

Fig. 6 Inhibition of different kinases by direct binding of flavonoids. The kinases invoved in cell survival, proliferation and metastasis of cells are grouped together.

\section{Conclusion}

$\nabla$

Overall, the studies described above provide evidence that fruits, vegetables, spices, nuts, and legumes comprise a vast array of biologically active flavonoids, many of which have been used in traditional medicine for thousands of years. The considerable evidence suggests that flavonoids in a diet rich in fruits and vegetables are associated with a decreased risk of inflammation-regulated chronic diseases, including cancer. Most of this evidence is preclinical, and more clinical trials are needed to further strengthen this evidence. Because most chronic diseases, including cancer, incubate for 20-30 years before they manifest, structuring such clinical trials will be difficult. It remains unknown what amount of flavonoids are needed and for how long and whether it is better to consume food with flavonoids or if supplements will suffice. The evidence, however, that these flavonoids are safe, multitargeted, efficacious, and affordable demands further investigation in cancer and other chronic diseases.

\section{References}

1 Jemal A, Siegel R, Ward E, Hao Y, Xu J, Thun MJ. Cancer statistics, 2009. CA Cancer J Clin 2009; 59: 225-249

2 Bray F, Moller B. Predicting the future burden of cancer. Nat Rev Cancer 2006; 6: 63-74

3 Aggarwal BB, Vijayalekshmi RV, Sung B. Targeting inflammatory pathways for prevention and therapy of cancer: short-term friend, longterm foe. Clin Cancer Res 2009; 15: 425-430

4 Ho R. AANCART comes to Hawaii. Hawaii Med J 2004; 63: 189-190, 193

5 Sen $R$, Baltimore $D$. Inducibility of kappa immunoglobulin enhancerbinding protein NF-kappa B by a posttranslational mechanism. Cell 1986; 47: 921-928

6 Karin $M$. The beginning of the end: IkappaB kinase (IKK) and NF-kappaB activation. J Biol Chem 1999; 274: 27339-27342

7 Pahl HL. Activators and target genes of Rel/NF-kappaB transcription factors. Oncogene 1999; 18: 6853-6866

8 Garg A, Aggarwal BB. Nuclear transcription factor-kappaB as a target for cancer drug development. Leukemia 2002; 16: 1053-1068
9 Kumar S, Sharma A, Madan B, Singhal V, Ghosh B. Isoliquiritigenin inhibits IkappaB kinase activity and ROS generation to block TNF-alpha induced expression of cell adhesion molecules on human endothelial cells. Biochem Pharmacol 2007; 73: 1602-1612

10 Orlowski RZ, Baldwin Jr AS. NF-kappaB as a therapeutic target in cancer. Trends Mol Med 2002; 8: 385-389

11 Valen G, Yan ZQ Hansson GK. Nuclear factor kappa-B and the heart. J Am Coll Cardiol 2001; 38: 307-314

12 Jones WK, Brown M, Ren X, He S, McGuinness M. NF-kappaB as an integrator of diverse signaling pathways: the heart of myocardial signaling? Cardiovasc Toxicol 2003; 3: 229-254

13 Shoelson SE, Lee J, Yuan M. Inflammation and the IKK beta/I kappa B/ NF-kappa B axis in obesity- and diet-induced insulin resistance. Int J Obes Relat Metab Disord 2003; 27 (Suppl. 3): S49-S52

14 Yang L, Cohn L, Zhang DH, Homer R, Ray A, Ray P. Essential role of nuclear factor kappaB in the induction of eosinophilia in allergic airway inflammation. J Exp Med 1998; 188: 1739-1750

15 Das J, Chen CH, Yang L, Cohn L, Ray P, Ray A. A critical role for NF-kappa B in GATA3 expression and TH2 differentiation in allergic airway inflammation. Nat Immunol 2001; 2: 45-50

16 Gagliardo R, Chanez P, Mathieu M, Bruno A, Costanzo G, Gougat C, Vachier I, Bousquet J, Bonsignore G, Vignola AM. Persistent activation of nuclear factor-kappaB signaling pathway in severe uncontrolled asthma. Am J Respir Crit Care Med 2003; 168: 1190-1198

17 Roshak AK, Callahan JF, Blake SM. Small-molecule inhibitors of NF-kap$\mathrm{paB}$ for the treatment of inflammatory joint disease. Curr Opin Pharmacol 2002; 2: 316-321

18 Lecleire S, Hassan A, Marion-Letellier R, Antonietti M, Savoye G, BôleFeysot C, Lerebours E, Ducrotté P, Déchelotte P, Coëffier M. Combined glutamine and arginine decrease proinflammatory cytokine production by biopsies from Crohn's patients in association with changes in nuclear factor-kappaB and p38 mitogen-activated protein kinase pathways. J Nutr 2008; 138: 2481-2486

19 Huang CJ, Nazarian R, Lee J, Zhao PM, Espinosa-Jeffrey A, de Vellis J. Tumor necrosis factor modulates transcription of myelin basic protein gene through nuclear factor kappa $\mathrm{B}$ in a human oligodendroglioma cell line. Int J Dev Neurosci 2002; 20: 289-296

20 Mattson MP, Camandola S. NF-kappaB in neuronal plasticity and neurodegenerative disorders. J Clin Invest 2001; 107: 247-254

21 Kaltschmidt B, Uherek M, Volk B, Baeuerle PA, Kaltschmidt C. Transcription factor NF-kappaB is activated in primary neurons by amyloid beta peptides and in neurons surrounding early plaques from patients with Alzheimer disease. Proc Natl Acad Sci USA 1997; 94: 2642-2647

22 Burke JR. Targeting I kappa B kinase for the treatment of inflammatory and other disorders. Curr Opin Drug Discov Devel 2003; 6: 720-728

23 Yamamoto Y, Gaynor RB. Therapeutic potential of inhibition of the NFkappaB pathway in the treatment of inflammation and cancer. J Clin Invest 2001; 107: 135-142

24 Gorman PN, Yao P, Seshadri V. Finding the answers in primary care: information seeking by rural and nonrural clinicians. Stud Health Technol Inform 2004; 107: 1133-1137

25 Balkwill $F$, Mantovani A. Inflammation and cancer: back to Virchow? Lancet 2001; 357: 539-545

26 Coussens LM, Werb Z. Inflammation and cancer. Nature 2002; 420 : 860-867

27 Kuper H, Adami HO, Trichopoulos D. Infections as a major preventable cause of human cancer. J Intern Med 2000; 248: 171-183

28 Hussain SP, Hofseth LJ, Harris CC. Radical causes of cancer. Nat Rev 2003; 3: $276-285$

29 de Visser KE, Eichten A, Coussens LM. Paradoxical roles of the immune system during cancer development. Nat Rev Cancer 2006; 6: 24-37

30 Castellarin SD, Di Gaspero G. Transcriptional control of anthocyanin biosynthetic genes in extreme phenotypes for berry pigmentation of naturally occurring grapevines. BMC Plant Biol 2007; 7: 46

31 Robak J, Gryglewski RJ. Bioactivity of flavonoids. Pol J Pharmacol 1996; 48: 555-564

32 Havsteen $B$. Flavonoids, a class of natural products of high pharmacological potency. Biochem Pharmacol 1983; 32: 1141-1148

33 Hrazdina G, Zobel AM, Hoch HC. Biochemical, immunological, and immunocytochemical evidence for the association of chalcone synthase with endoplasmic reticulum membranes. Proc Natl Acad Sci USA 1987; 84: 8966-8970 
34 Ververidis F, Trantas E, Douglas C, Vollmer G, Kretzschmar G, Panopoulos $N$. Biotechnology of flavonoids and other phenylpropanoid-derived natural products. Part II: reconstruction of multienzyme pathways in plants and microbes. Biotechnol J 2007; 2: 1235-1249

35 Wilmouth RC, Turnbull JJ, Welford RW, Clifton IJ, Prescott AG, Schofield CJ. Structure and mechanism of anthocyanidin synthase from Arabidopsis thaliana. Structure 2002; 10: 93-103

36 Turnbull WB, Pease AR, Stoddart JF. Toward the synthesis of large oligosaccharide-based dendrimers. Chembiochem 2000; 1: 70-74

37 Saito K, Kobayashi M, Gong Z, Tanaka Y, Yamazaki M. Direct evidence for anthocyanidin synthase as a 2-oxoglutarate-dependent oxygenase: molecular cloning and functional expression of cDNA from a red forma of Perilla frutescens. Plant J 1999; 17: 181-189

38 Kitamura S, Shikazono N, Tanaka A. TRANSPARENT TESTA 19 is involved in the accumulation of both anthocyanins and proanthocyanidins in Arabidopsis. Plant J 2004; 37: 104-114

39 Manach C, Scalbert A, Morand C, Remesy C, Jimenez L. Polyphenols: food sources and bioavailability. Am J Clin Nutr 2004; 79: 727-747

40 Hollman PC, van Trijp JM, Buysman MN, van der Gaag MS, Mengelers MJ, de Vries JH, Katan MB. Relative bioavailability of the antioxidant flavonoid quercetin from various foods in man. FEBS Lett 1997; 418: 152156

41 Guy L, Vedrine N, Urpi-Sarda M, Gil-Izquierdo A, Al-Maharik N, Boiteux $J P$, Scalbert A, Rémésy C, Botting NC, Manach C. Orally administered isoflavones are present as glucuronides in the human prostate. Nutr Cancer 2008; 60: 461-468

42 Dalais FS, Meliala A, Wattanapenpaiboon N, Frydenberg M, Suter DA, Thomson WK, Wahlqvist ML. Effects of a diet rich in phytoestrogens on prostate-specific antigen and sex hormones in men diagnosed with prostate cancer. Urology 2004; 64: 510-515

43 Bettuzzi S, Brausi M, Rizzi F, Castagnetti G, Peracchia G, Corti A. Chemoprevention of human prostate cancer by oral administration of green tea catechins in volunteers with high-grade prostate intraepithelial neoplasia: a preliminary report from a one-year proof-of-principle study. Cancer Res 2006; 66: 1234-1240

44 Flaig TW, Gustafson DL, Su LJ, Zirrolli JA, Crighton F, Harrison GS, Pierson AS, Agarwal R, Glodé LM. A phase I and pharmacokinetic study of silybin-phytosome in prostate cancer patients. Invest New Drugs 2007; 25: $139-146$

45 Flaig TW, Glode M, Gustafson D, van Bokhoven A, Tao Y, Wilson S, Su LJ, Li Y, Harrison G, Agarwal R, Crawford ED, Lucia MS, Pollak M. A study of high-dose oral silybin-phytosome followed by prostatectomy in patients with localized prostate cancer. The Prostate 2010; 70: 848-855

46 Felgines C, Texier O, Morand C, Manach C, Scalbert A, Régerat F, Rémésy C. Bioavailability of the flavanone naringenin and its glycosides in rats. Am J Physiol Gastrointest Liver Physiol 2000; 279: G1148-G1154

47 Son TG, Camandola S, Mattson MP. Hormetic dietary phytochemicals. Neuromol Med 2008; 10: 236-246

48 Utesch D, Feige K, Dasenbrock J, Broschard TH, Harwood M, Danielews$\mathrm{ka}$-Nikiel B, Lines TC. Evaluation of the potential in vivo genotoxicity of quercetin. Mutat Res 2008; 654: 38-44

49 Shen $K H$, Chang JK, Hsu YL, Kuo PL. Chalcone arrests cell cycle progression and induces apoptosis through induction of mitochondrial pathway and inhibition of nuclear factor kappa B signalling in human bladder cancer cells. Basic Clin Pharmacol Toxicol 2007; 101: 254-261

50 Liu YC, Hsieh CW, Wu CC, Wung BS. Chalcone inhibits the activation of NF-kappaB and STAT3 in endothelial cells via endogenous electrophile. Life Sci 2007; 80: 1420-1430

51 Abuarqoub H, Foresti R, Green CJ, Motterlini R. Heme oxygenase-1 mediates the anti-inflammatory actions of 2'-hydroxychalcone in RAW 264.7 murine macrophages. Am J Physiol Cell Physiol 2006; 290: C1092-C1099

52 Lee SH, Seo GS, Kim JY, Jin XY, Kim HD, Sohn DH. Heme oxygenase 1 mediates anti-inflammatory effects of $2^{\prime}, 4^{\prime}, 6^{\prime}$-tris(methoxymethoxy) chalcone. Eur J Pharmacol 2006; 532: 178-186

53 Ban HS, Suzuki K, Lim SS, Jung SH, Lee S, Ji J, Lee HS, Lee YS, Shin KH, Ohuchi $K$. Inhibition of lipopolysaccharide-induced expression of inducible nitric oxide synthase and tumor necrosis factor-alpha by 2'-hydroxychalcone derivatives in RAW 264.7 cells. Biochem Pharmacol 2004; 67: $1549-1557$

54 Kim JB, Han AR, Park EY, Kim JY, Cho W, Lee J, Seo EK, Lee KT. Inhibition of LPS-induced iNOS, COX-2 and cytokines expression by poncirin through the NF-kappaB inactivation in RAW 264.7 macrophage cells. Biol Pharm Bull 2007; 30: 2345-2351
55 Sung B, Pandey MK, Aggarwal BB. Fisetin, an inhibitor of cyclin-dependent kinase 6 , down-regulates nuclear factor-kappaB-regulated cell proliferation, antiapoptotic and metastatic gene products through the suppression of TAK-1 and receptor-interacting protein-regulated IkappaBalpha kinase activation. Mol Pharmacol 2007; 71: 1703-1714

56 Kunnumakkara AB, Nair AS, Ahn KS, Pandey MK, Yi Z, Liu M, Aggarwal $B B$. Gossypin, a pentahydroxy glucosyl flavone, inhibits the transforming growth factor beta-activated kinase-1-mediated NF-kappaB activation pathway, leading to potentiation of apoptosis, suppression of invasion, and abrogation of osteoclastogenesis. Blood 2007; 109: 51125121

57 Ju W, Wang X, Shi H, Chen W, Belinsky SA, Lin Y. A critical role of luteolin-induced reactive oxygen species in blockage of tumor necrosis factor-activated nuclear factor-kappaB pathway and sensitization of apoptosis in lung cancer cells. Mol Pharmacol 2007; 71: 1381-1388

58 Pan MH, Lai CS, Wang YJ, Ho CT. Acacetin suppressed LPS-induced upexpression of iNOS and COX-2 in murine macrophages and TPA-induced tumor promotion in mice. Biochem Pharmacol 2006; 72: 1293-1303

59 Shukla S, Gupta S. Suppression of constitutive and tumor necrosis factor alpha-induced nuclear factor (NF)-kappaB activation and induction of apoptosis by apigenin in human prostate carcinoma PC-3 cells: correlation with down-regulation of NF-kappaB-responsive genes. Clin Cancer Res 2004; 10: 3169-3178

60 Romier B, Van De Walle J, During A, Larondelle Y, Schneider YJ. Modulation of signalling nuclear factor-kappaB activation pathway by polyphenols in human intestinal Caco-2 cells. Brit J Nutr 2008; 100: 542551

61 Cheng PY, Lee YM, Wu YS, Chang TW, Jin JS, Yen MH. Protective effect of baicalein against endotoxic shock in rats in vivo and in vitro. Biochem Pharmacol 2007; 73: 793-804

62 Nakamura N, Hayasaka S, Zhang XY, Nagaki Y, Matsumoto M, Hayasaka $Y$, Terasawa $K$. Effects of baicalin, baicalein, and wogonin on interleukin- 6 and interleukin- 8 expression, and nuclear factor-kappaB binding activities induced by interleukin-1beta in human retinal pigment epithelial cell line. Exp Eye Res 2003; 77: 195-202

63 Burnett BP, Jia Q Zhao Y, Levy RM. A medicinal extract of Scutellaria baicalensis and Acacia catechu acts as a dual inhibitor of cyclooxygenase and 5-lipoxygenase to reduce inflammation. J Med Food 2007; 10: $442-451$

64 Li BQ Fu T, Gong WH, Dunlop N, Kung H, Yan Y, Kang J, Wang JM. The flavonoid baicalin exhibits anti-inflammatory activity by binding to chemokines. Immunopharmacology 2000; 49: 295-306

65 Aquila S, Giner RM, Recio MC, Spegazzini ED, Rios JL. Anti-inflammatory activity of flavonoids from Cayaponia tayuya roots. J Ethnopharmacol 2009; 121: 333-337

66 Huang ST, Chen CT, Chieng KT, Huang SH, Chiang BH, Wang LF, Kuo HS, Lin CM. Inhibitory effects of a rice hull constituent on tumor necrosis factor alpha, prostaglandin E2, and cyclooxygenase-2 production in lipopolysaccharide-activated mouse macrophages. Ann NY Acad Sci 2005; 1042: 387-395

67 Takada Y, Aggarwal BB. Flavopiridol inhibits NF-kappaB activation induced by various carcinogens and inflammatory agents through inhibition of IkappaBalpha kinase and p 65 phosphorylation: abrogation of cyclin D1, cyclooxygenase-2, and matrix metalloprotease-9. J Biol Chem 2004; 279: 4750-4759

68 Messmann RA, Ullmann CD, Lahusen T, Kalehua A, Wasfy J, Melillo G, Ding I, Headlee D, Figg WD, Sausville EA, Senderowicz AM. Flavopiridolrelated proinflammatory syndrome is associated with induction of interleukin-6. Clin Cancer Res 2003; 9: 562-570

69 Kim HP, Park H, Son KH, Chang HW, Kang SS. Biochemical pharmacology of biflavonoids: implications for anti-inflammatory action. Arch Pharm Res 2008; 31: 265-273

70 Suh SJ, Jin UH, Kim SH, Chang HW, Son JK, Lee SH, Son KH, Kim CH. Ochnaflavone inhibits TNF-alpha-induced human VSMC proliferation via regulation of cell cycle, ERK1/2, and MMP-9. J Cell Biochem 2006; 99: $1298-1307$

71 Lee KW, Kang NJ, Heo YS, Rogozin EA, Pugliese A, Hwang MK, Bowden GT, Bode AM, Lee HJ, Dong Z. Raf and MEK protein kinases are direct molecular targets for the chemopreventive effect of quercetin, a major flavonol in red wine. Cancer Res 2008; 68: 946-955

72 Lee KW, Kang NJ, Rogozin EA, Kim HG, Cho YY, Bode AM, Lee HJ, Surh YJ, Bowden GT, Dong Z. Myricetin is a novel natural inhibitor of neoplastic cell transformation and MEK1. Carcinogenesis 2007; 28: 1918-1927 
73 Muñoz-Espada AC, Watkins BA. Cyanidin attenuates PGE2 production and cyclooxygenase-2 expression in LNCaP human prostate cancer cells. J Nutr Biochem 2006; 17: 589-596

$74 \mathrm{Xu} \mathrm{W,} \mathrm{Liu} \mathrm{J,} \mathrm{Li} \mathrm{C,} \mathrm{Wu} \mathrm{HZ,} \mathrm{Liu} \mathrm{YW.} \mathrm{Kaempferol-7-O-beta-D-glucoside}$ (KG) isolated from Smilax china L. rhizome induces G2/M phase arrest and apoptosis on HeLa cells in a p 53-independent manner. Cancer Lett 2008; 264: 229-240

75 Hamalainen M, Nieminen R, Vuorela P, Heinonen M, Moilanen E. Anti-inflammatory effects of flavonoids: genistein, kaempferol, quercetin, and daidzein inhibit STAT-1 and NF-kappaB activations, whereas flavone, isorhamnetin, naringenin, and pelargonidin inhibit only NF-kappaB activation along with their inhibitory effect on iNOS expression and NO production in activated macrophages. Mediators Inflamm 2007; 2007: 45673

76 Kim JY, Jung KJ, Choi JS, Chung HY. Modulation of the age-related nuclear factor-kappaB (NF-kappaB) pathway by hesperetin. Aging Cell 2006; 5: 401-411

77 Singh RP, Mallikarjuna GU, Sharma G, Dhanalakshmi S, Tyagi AK, Chan DC, Agarwal C, Agarwal R. Oral silibinin inhibits lung tumor growth in athymic nude mice and forms a novel chemocombination with doxorubicin targeting nuclear factor kappaB-mediated inducible chemoresistance. Clin Cancer Res 2004; 10: 8641-8647

78 Bito T, Roy S, Sen CK, Shirakawa T, Gotoh A, Ueda M, Ichihashi M, Packer L. Flavonoids differentially regulate IFN gamma-induced ICAM-1 expression in human keratinocytes: molecular mechanisms of action. FEBS Lett 2002; 520: 145-152

79 Ferrandiz ML, Gil B, Sanz MJ, Ubeda A, Erazo S, González E, Negrete R, Pacheco S, Payá M, Alcaraz MJ. Effect of bakuchiol on leukocyte functions and some inflammatory responses in mice. J Pharm Pharmacol 1996; 48: 975-980

80 Rajakangas J, Misikangas M, Paivarinta E, Mutanen M. Chemoprevention by white currant is mediated by the reduction of nuclear beta-catenin and NF-kappaB levels in Min mice adenomas. Eur J Nutr 2008; 47: 115-122

81 Boivin D, Blanchette M, Barrette S, Moghrabi A, Beliveau R. Inhibition of cancer cell proliferation and suppression of TNF-induced activation of NFkappaB by edible berry juice. Anticancer Res 2007; 27: 937-948

82 Chen PN, Kuo WH, Chiang CL, Chiou HL, Hsieh YS, Chu SC. Black rice anthocyanins inhibit cancer cells invasion via repressions of MMPs and u-PA expression. Chem Biol Interact 2006; 163: 218-229

83 Chen PN, Chu SC, Chiou HL, Kuo WH, Chiang CL, Hsieh YS. Mulberry anthocyanins, cyanidin 3-rutinoside and cyanidin 3-glucoside, exhibited an inhibitory effect on the migration and invasion of a human lung cancer cell line. Cancer Lett 2006; 235: 248-259

84 Afaq F, Malik A, Syed D, Maes D, Matsui MS, Mukhtar H. Pomegranate fruit extract modulates UV-B-mediated phosphorylation of mitogenactivated protein kinases and activation of nuclear factor kappa B in normal human epidermal keratinocytes paragraph sign. Photochem Photobiol 2005; 81: 38-45

85 Kang JL, Lee HW, Lee HS, Pack IS, Chong Y, Castranova V, Koh Y. Genistein prevents nuclear factor-kappa B activation and acute lung injury induced by lipopolysaccharide. Am J Respir Crit Care Med 2001; 164 : 2206-2212

86 Kang JS, Yoon YD, Han MH, Han SB, Lee K, Kang MR, Moon EY, Jeon YJ, Park SK, Kim HM. Estrogen receptor-independent inhibition of tumor necrosis factor-alpha gene expression by phytoestrogen equol is mediated by blocking nuclear factor-kappaB activation in mouse macrophages. Biochem Pharmacol 2005; 71: 136-143

87 Manna SK, Aggarwal RS, Sethi G, Aggarwal BB, Ramesh GT. Morin (3,5, 7,2',4'-pentahydroxyflavone) abolishes nuclear factor-kappaB activation induced by various carcinogens and inflammatory stimuli, leading to suppression of nuclear factor-kappaB-regulated gene expression and up-regulation of apoptosis. Clin Cancer Res 2007; 13: 2290-2297

88 Tabary O, Escotte S, Couetil JP, Hubert D, Dusser D, Puchelle E, Jacquot J. Relationship between IkappaBalpha deficiency, NFkappaB activity and interleukin-8 production in CF human airway epithelial cells. Pflugers Arch 2001; 443 (Suppl. 1): S40-S44

89 Kang IS, Yoon YD, Cho IJ, Han MH, Lee CW, Park SK, Kim HM. Glabridin, an isoflavan from licorice root, inhibits inducible nitric-oxide synthase expression and improves survival of mice in experimental model of septic shock. J Pharmacol Exp Ther 2005; 312: 1187-1194

90 Ahn KS, Noh EJ, Cha KH, Kim YS, Lim SS, Shin KH, Jung SH. Inhibitory effects of irigenin from the rhizomes of Belamcanda chinensis on nitric oxide and prostaglandin $\mathrm{E}(2)$ production in murine macrophage RAW 264.7 cells. Life Sci 2006; 78: 2336-2342
91 De Melo GO, Muzitano MF, Legora-Machado A, Almeida TA, De Oliveira DB, Kaiser CR, Koatz VL, Costa SS. C-glycosylflavones from the aerial parts of Eleusine indica inhibit LPS-induced mouse lung inflammation. Planta Med 2005; 71: 362-363

92 Chen $\mathrm{KH}$, Weng MS, Lin JK. Tangeretin suppresses IL-1beta-induced cyclooxygenase (COX)-2 expression through inhibition of p 38 MAPK, JNK, and AKT activation in human lung carcinoma cells. Biochem Pharmacol 2007; 73: 215-227

93 Tuchinda P, Saiai A, Pohmakotr M, Yoosook C, Kasisit J, Napaswat C, Santisuk T, Reutrakul V. Anti-HIV-1 cycloartanes from leaves and twigs of Gardenia thailandica. Planta Med 2004; 70: 366-370

94 Lowe SW, Lin AW. Apoptosis in cancer. Carcinogenesis 2000; 21: 485495

95 Shishodia S, Aggarwal BB. Nuclear factor-kappaB activation mediates cellular transformation, proliferation, invasion angiogenesis and metastasis of cancer. Cancer Treat Res 2004; 119: 139-173

96 Dorn C, Kraus B, Motyl M, Weiss TS, Gehrig M, Schölmerich J, Heilmann J, Hellerbrand $C$. Xanthohumol, a chalcon derived from hops, inhibits hepatic inflammation and fibrosis. Mol Nutr Food Res, in press

97 Harikumar KB, Kunnumakkara AB, Ahn KS, Anand P, Krishnan S, Guha $S$, Aggarwal BB. Modification of the cysteine residues in IkappaBalpha kinase and NF-kappaB (p 65) by xanthohumol leads to suppression of NF-kappaB-regulated gene products and potentiation of apoptosis in leukemia cells. Blood 2009; 113: 2003-2013

98 Pandey MK, Sung B, Ahn KS, Aggarwal BB. Butein suppresses constitutive and inducible signal transducer and activator of transcription (STAT) 3 activation and STAT3-regulated gene products through the induction of a protein tyrosine phosphatase SHP-1. Mol Pharmacol 2009; 75: 525-533

99 Wang $Y$, Chan FL, Chen S, Leung LK. The plant polyphenol butein inhibits testosterone-induced proliferation in breast cancer cells expressing aromatase. Life Sci 2005; 77: 39-51

100 Hsu YL, Kuo PL, Chiang LC, Lin CC. Isoliquiritigenin inhibits the proliferation and induces the apoptosis of human non-small cell lung cancer a549 cells. Clin Exp Pharmacol Physiol 2004; 31: 414-418

101 Kanazawa M, Satomi Y, Mizutani Y, Ukimura O, Kawauchi A, Sakai T, Baba M, Okuyama T, Nishino H, Miki T. Isoliquiritigenin inhibits the growth of prostate cancer. Eur Urol 2003; 43: 580-586

$102 \mathrm{Ma}$ J, Fu NY, Pang DB, Wu WY, Xu AL. Apoptosis induced by isoliquiritigenin in human gastric cancer MGC-803 cells. Planta Med 2001; 67: 754-757

103 Yamazaki S, Morita T, Endo H, Hamamoto T, Baba M, Joichi Y, Kaneko S, Okada Y, Okuyama T, Nishino H, Tokue A. Isoliquiritigenin suppresses pulmonary metastasis of mouse renal cell carcinoma. Cancer Lett 2002; 183: 23-30

104 Kimura Y, Taniguchi M, Baba K. Antitumor and antimetastatic activities of 4-hydroxyderricin isolated from Angelica keiskei roots. Planta Med 2004; 70: 211-219

105 Kimura Y, Baba K. Antitumor and antimetastatic activities of Angelica keiskei roots, part 1: isolation of an active substance, xanthoangelol. Int J Cancer 2003; 106: 429-437

106 Lee YS, Lim SS, Shin KH, Kim YS, Ohuchi K, Jung SH. Anti-angiogenic and anti-tumor activities of 2'-hydroxy-4'-methoxychalcone. Biol Pharm Bull 2006; 29: 1028-1031

107 Li ZD, Hu XW, Wang YT, Fang J. Apigenin inhibits proliferation of ovarian cancer A2780 cells through Id1. FEBS Lett 2009; 583: 1999-2003

108 Franzen CA, Amargo E, Todorovic V, Desai BV, Huda S, Mirzoeva S, Chiu K, Grzybowski BA, Chew TL, Green KJ, Pelling JC. The chemopreventive bioflavonoid apigenin inhibits prostate cancer cell motility through the focal adhesion kinase/Src signaling mechanism. Cancer Prev Res (Phila Pa) 2009; 2: 830-841

$109 \mathrm{Hu}$ XW, Meng D, Fang J. Apigenin inhibited migration and invasion of human ovarian cancer A2780 cells through focal adhesion kinase. Carcinogenesis 2008; 29: 2369-2376

110 Lee WJ, Chen WK, Wang CJ, Lin WL, Tseng TH. Apigenin inhibits HGFpromoted invasive growth and metastasis involving blocking PI3K/ Akt pathway and beta 4 integrin function in MDA-MB-231 breast cancer cells. Toxicol Appl Pharmacol 2008; 226: 178-191

111 Androutsopoulos VP, Mahale S, Arroo RR, Potter G. Anticancer effects of the flavonoid diosmetin on cell cycle progression and proliferation of MDA-MB 468 breast cancer cells due to CYP1 activation. Oncol Rep 2009; 21: 1525-1528

112 Lin $Y$, Shi $R$, Wang $X$, Shen HM. Luteolin, a flavonoid with potential for cancer prevention and therapy. Curr Cancer Drug Targets 2008; 8: 634-646 
113 Wu B, Zhang $Q$ Shen $W$, Zhu J. Anti-proliferative and chemosensitizing effects of luteolin on human gastric cancer AGS cell line. Mol Cell Biochem 2008; 313: 125-132

114 Bagli E, Stefaniotou M, Morbidelli L, Ziche M, Psillas K, Murphy C, Fotsis $T$. Luteolin inhibits vascular endothelial growth factor-induced angiogenesis; inhibition of endothelial cell survival and proliferation by targeting phosphatidylinositol 3'-kinase activity. Cancer Res 2004; 64: 7936-7946

115 Zhou Q Yan B, Hu X, Li XB, Zhang J, Fang J. Luteolin inhibits invasion of prostate cancer PC3 cells through E-cadherin. Mol Cancer Ther 2009; 8: 1684-1691

116 Chang HL, Su JH, Yeh YT, Lee YC, Chen HM, Wu YC, Yuan SS. Protoapigenone, a novel flavonoid, inhibits ovarian cancer cell growth in vitro and in vivo. Cancer Lett 2008; 267: 85-95

117 Luo G, Guan X, Zhou L. Apoptotic effect of citrus fruit extract nobiletin on lung cancer cell line A549 in vitro and in vivo. Cancer Biol Ther 2008; 7: 966-973

118 Miyata Y, Sato T, Yano M, Ito A. Activation of protein kinase $C$ betaII/ epsilon-C-Jun NH2-terminal kinase pathway and inhibition of mitogen-activated protein/extracellular signal-regulated kinase $1 / 2$ phosphorylation in antitumor invasive activity induced by the polymethoxy flavonoid, nobiletin. Mol Cancer Ther 2004; 3: 839-847

119 Miyata Y, Sato T, Imada K, Dobashi A, Yano M, Ito A. A citrus polymethoxyflavonoid, nobiletin, is a novel MEK inhibitor that exhibits antitumor metastasis in human fibrosarcoma HT-1080 cells. Biochem Biophys Res Commun 2008; 366: 168-173

120 Morley KL, Ferguson PJ, Koropatnick J. Tangeretin and nobiletin induce G1 cell cycle arrest but not apoptosis in human breast and colon cancer cells. Cancer Lett 2007; 251: 168-178

121 Bracke ME, Vyncke BM, Van Larebeke NA, Bruyneel EA, De Bruyne GK, De Pestel GH, De Coster WJ, Espeel MF, Mareel MM. The flavonoid tangeretin inhibits invasion of MO4 mouse cells into embryonic chick heart in vitro. Clin Exp Metastasis 1989; 7: 283-300

122 Murillo G, Hirschelman WH, Ito A, Moriarty RM, Kinghorn AD, Pezzuto JM, Mehta RG. Zapotin, a phytochemical present in a Mexican fruit, prevents colon carcinogenesis. Nutr Cancer 2007; 57: 28-37

123 Pan MH, Lai CS, Hsu PC, Wang YJ. Acacetin induces apoptosis in human gastric carcinoma cells accompanied by activation of caspase cascades and production of reactive oxygen species. J Agric Food Chem 2005; 53: $620-630$

124 Singh RP, Agrawal P, Yim D, Agarwal C, Agarwal R. Acacetin inhibits cell growth and cell cycle progression, and induces apoptosis in human prostate cancer cells: structure-activity relationship with linarin and linarin acetate. Carcinogenesis 2005; 26: 845-854

125 Yang SF, Yang WE, Kuo WH, Chang HR, Chu SC, Hsieh YS. Antimetastatic potentials of flavones on oral cancer cell via an inhibition of matrixdegrading proteases. Arch Oral Biol 2008; 53: 287-294

126 Arafa el-SA, Zhu Q Barakat BM, Wani G, Zhao Q El-Mahdy MA, Wani $A A$. Tangeretin sensitizes cisplatin-resistant human ovarian cancer cells through downregulation of phosphoinositide 3-kinase/Akt signaling pathway. Cancer Res 2009; 69: 8910-8917

127 Peng CY, Pan SL, Huang YW, Guh JH, Chang YL, Teng CM. Baicalein attenuates intimal hyperplasia after rat carotid balloon injury through arresting cell-cycle progression and inhibiting ERK, Akt, and NF-kappaB activity in vascular smooth-muscle cells. Naunyn Schmiedebergs Arch Pharmacol 2008; 378: 579-588

128 Androutsopoulos VP, Ruparelia K, Arroo RR, Tsatsakis AM, Spandidos DA. CYP1-mediated antiproliferative activity of dietary flavonoids in MDA-MB-468 breast cancer cells. Toxicology 2009; 264: 162-170

129 Du G, Han G, Zhang S, Lin H, Wu X, Wang M, Ji L, Lu L, Yu L, Liang W. Baicalin suppresses lung carcinoma and lung metastasis by SOD mimic and HIF-1alpha inhibition. Eur J Pharmacol 2010; 630: 121130

130 Li Y, Bhuiyan M, Alhasan S, Senderowicz AM, Sarkar FH. Induction of apoptosis and inhibition of c-erbB-2 in breast cancer cells by flavopiridol. Clin Cancer Res 2000; 6: 223-229

131 Luo H, Rankin GO, Liu L, Daddysman MK, Jiang BH, Chen YC. Kaempferol inhibits angiogenesis and VEGF expression through both HIF dependent and independent pathways in human ovarian cancer cells. Nutr Cancer 2009; 61: 554-563

132 Li W, Du B, Wang T, Wang S, Zhang J. Kaempferol induces apoptosis in human HCT116 colon cancer cells via the ataxia-telangiectasia mutated-p 53 pathway with the involvement of p 53 upregulated modulator of apoptosis. Chem Biol Interact 2009; 177: 121-127
133 Chien SY, Wu YC, Chung JG, Yang JS, Lu HF, Tsou MF, Wood W, Kuo SJ, Chen DR. Quercetin-induced apoptosis acts through mitochondrialand caspase-3-dependent pathways in human breast cancer MDA-MB-231 cells. Hum Exp Toxicol 2009; 28: 493-503

134 Tan J, Wang B, Zhu L. Regulation of survivin and Bcl-2 in HepG2 cell apoptosis induced by quercetin. Chem Biodivers 2009; 6: 1101-1110

135 Shan BE, Wang MX, Li RQ. Quercetin inhibit human SW480 colon cancer growth in association with inhibition of cyclin D1 and survivin expression through Wnt/beta-catenin signaling pathway. Cancer Invest 2009; 27: 604-612

136 Zhang W, Zhang $F$. Effects of quercetin on proliferation, apoptosis, adhesion and migration, and invasion of HeLa cells. Eur J Gynaecol Oncol 2009; 30: 60-64

137 Siegelin MD, Reuss DE, Habel A, Rami A, von Deimling A. Quercetin promotes degradation of survivin and thereby enhances death-receptormediated apoptosis in glioma cells. Neuro Oncol 2009; 11: 122-131

138 Kim EJ, Choi CH, Park JY, Kang SK, Kim YK. Underlying mechanism of quercetin-induced cell death in human glioma cells. Neurochem Res 2008; 33: 971-979

139 van der Woude H, Ter Veld MG, Jacobs N, van der Saag PT, Murk AJ, Rietjens IM. The stimulation of cell proliferation by quercetin is mediated by the estrogen receptor. Mol Nutr Food Res 2005; 49: 763-771

140 Amado NG, Cerqueira DM, Menezes FS, da Silva JF, Neto VM, Abreu JG. Isoquercitrin isolated from Hyptis fasciculata reduces glioblastoma cell proliferation and changes beta-catenin cellular localization. Anticancer Drugs 2009; 20: 543-552

141 Lin JP, Yang JS, Lu CC, Chiang JH, Wu CL, Lin JJ, Lin HL, Yang MD, Liu KC, Chiu TH, Chung JG. Rutin inhibits the proliferation of murine leukemia WEHI- 3 cells in vivo and promotes immune response in vivo. Leuk Res 2009; 33: 823-828

142 Ali HA, Chowdhury AK, Rahman AK, Borkowski T, Nahar L, Sarker SD. Pachypodol, a flavonol from the leaves of Calycopteris floribunda, inhibits the growth of $\mathrm{CaCo}-2$ colon cancer cell line in vitro. Phytother Res 2008; 22: 1684-1687

143 van Ginkel PR, Sareen D, Subramanian L, Walker Q Darjatmoko SR, Lindstrom MJ, Kulkarni A, Albert DM, Polans AS. Resveratrol inhibits tumor growth of human neuroblastoma and mediates apoptosis by directly targeting mitochondria. Clin Cancer Res 2007; 13: 51625169

144 Cecchinato V, Chiaramonte R, Nizzardo M, Cristofaro B, Basile A, Sherbet GV, Comi P. Resveratrol-induced apoptosis in human T-cell acute lymphoblastic leukaemia MOLT-4 cells. Biochem Pharmacol 2007; 74: 1568-1574

145 Marel AK, Lizard G, Izard JC, Latruffe N, Delmas D. Inhibitory effects of trans-resveratrol analogs molecules on the proliferation and the cell cycle progression of human colon tumoral cells. Mol Nutr Food Res 2008; 52: 538-548

146 Roccaro AM, Leleu X, Sacco A, Moreau AS, Hatjiharissi E, Jia X, Xu L, Ciccarelli B, Patterson CJ, Ngo HT, Russo D, Vacca A, Dammacco F, Anderson $K C$, Ghobrial IM, Treon SP. Resveratrol exerts antiproliferative activity and induces apoptosis in Waldenstrom's macroglobulinemia. Clin Cancer Res 2008: 14: 1849-1858

147 Zhao W, Bao P, Qi H, You H. Resveratrol down-regulates survivin and induces apoptosis in human multidrug-resistant SPC-A-1/CDDP cells. Oncol Rep 2010; 23: 279-286

148 Schlachterman A, Valle F, Wall KM, Azios NG, Castillo L, Morell L, Washington AV, Cubano LA, Dharmawardhane SF. Combined resveratrol, quercetin, and catechin treatment reduces breast tumor growth in a nude mouse model. Transl Oncol 2008; 1: 19-27

149 Castillo-Pichardo L, Martinez-Montemayor MM, Martinez JE, Wall KM, Cubano LA, Dharmawardhane S. Inhibition of mammary tumor growth and metastases to bone and liver by dietary grape polyphenols. Clin Exp Metastasis 2009; 26: 505-516

150 De Leo M, Braca A, Sanogo R, Cardile V, DeTommasi N, Russo A. Antiproliferative activity of Pteleopsis suberosa leaf extract and its flavonoid components in human prostate carcinoma cells. Planta Med 2006; 72: 604-610

151 Lin J, Zhang SM, Wu K, Willett WC, Fuchs CS, Giovannucci E. Flavonoid intake and colorectal cancer risk in men and women. Am J Epidemiol 2006; 164: 644-651

152 Ko CH, Shen SC, Lin HY, Hou WC, Lee WR, Yang LL, Chen YC. Flavanones structure-related inhibition on TPA-induced tumor promotion through suppression of extracellular signal-regulated protein kinases: involvement of prostaglandin E2 in anti-promotive process. J Cell Physiol 2002; 193: 93-102 
153 Hsiao YC, Kuo WH, Chen PN, Chang HR, Lin TH, Yang WE, Hsieh YS, Chu SC. Flavanone and 2'-OH flavanone inhibit metastasis of lung cancer cells via down-regulation of proteinases activities and MAPK pathway. Chem Biol Interact 2007; 167: 193-206

154 Virgili F, Acconcia F, Ambra R, Rinna A, Totta P, Marino M. Nutritional flavonoids modulate estrogen receptor alpha signaling. IUBMB Life 2004; 56: 145-151

155 Bulzomi P, Bolli A, Galluzzo P, Leone S, Acconcia F, Marino M. Naringenin and 17beta-estradiol coadministration prevents hormone-induced human cancer cell growth. IUBMB Life 2010; 62: 51-60

156 Totta P, Acconcia F, Leone S, Cardillo I, Marino M. Mechanisms of naringenin-induced apoptotic cascade in cancer cells: involvement of estrogen receptor alpha and beta signalling. IUBMB Life 2004; 56: 491499

157 Deep G, Singh RP, Agarwal C, Kroll DJ, Agarwal R. Silymarin and silibinin cause G1 and G2-M cell cycle arrest via distinct circuitries in human prostate cancer PC3 cells: a comparison of flavanone silibinin with flavanolignan mixture silymarin. Oncogene 2006; 25: 10531069

158 Dorta DJ, Pigoso AA, Mingatto FE, Rodrigues T, Prado IM, Helena AF, Uyemura SA, Santos AC, Curti $C$. The interaction of flavonoids with mitochondria: effects on energetic processes. Chem Biol Interact 2005; 152: 67-78

159 Choi EJ, Lee JI, Kim GH. Anti-carcinogenic effect of a new analogue 4'chloroflavanone from flavanone in human breast cancer cells. Int J Mol Med 2010; 25: 293-298

160 Rho YH, Lee BW, Park KH, Bae YS. Cudraflavanone A purified from Cudrania tricuspidata induces apoptotic cell death of human leukemia U937 cells, at least in part, through the inhibition of DNA topoisomerase I and protein kinase C activity. Anticancer Drugs 2007; 18: 10231028

161 He Q Li R, Fang L, Ying H, Hu Y, Yang B. Antileukemia activity of MSFTZ-a novel flavanone analog. Anticancer Drugs 2006; 17: 641647

162 Singletary KW, Stansbury MJ, Giusti M, Van Breemen RB, Wallig M, Rimando $A$. Inhibition of rat mammary tumorigenesis by concord grape juice constituents. J Agric Food Chem 2003; 51: 7280-7286

163 Cai H, Marczylo TH, Teller N, Brown K, Steward WP, Marko D, Gescher AJ. Anthocyanin-rich red grape extract impedes adenoma development in the Apc(Min) mouse: pharmacodynamic changes and anthocyanin levels in the murine biophase. Eur J Cancer 2010; 46: 811-817

164 Seeram NP, Adams LS, Hardy ML, Heber D. Total cranberry extract versus its phytochemical constituents: antiproliferative and synergistic effects against human tumor cell lines. J Agric Food Chem 2004; 52 : 2512-2517

165 Olsson ME, Gustavsson KE, Andersson S, Nilsson A, Duan RD. Inhibition of cancer cell proliferation in vitro by fruit and berry extracts and correlations with antioxidant levels. J Agric Food Chem 2004; 52: 72647271

166 Afaq F, Syed DN, Malik A, Hadi N, Sarfaraz S, Kweon MH, Khan N, Zaid MA, Mukhtar H. Delphinidin, an anthocyanidin in pigmented fruits and vegetables, protects human $\mathrm{HaCaT}$ keratinocytes and mouse skin against UVB-mediated oxidative stress and apoptosis. J Invest Dermatol 2007; 127: 222-232

167 Reddivari L, Vanamala J, Chintharlapalli S, Safe SH, Miller Jr JC. Anthocyanin fraction from potato extracts is cytotoxic to prostate cancer cells through activation of caspase-dependent and caspase-independent pathways. Carcinogenesis 2007; 28: 2227-2235

168 Martin S, Giannone G, Andriantsitohaina R, Martinez MC. Delphinidin, an active compound of red wine, inhibits endothelial cell apoptosis via nitric oxide pathway and regulation of calcium homeostasis. $\mathrm{Br}$ J Pharmacol 2003; 139: 1095-1102

169 Kuo PL, Hsu YL, Lin TC, Lin CC. The antiproliferative activity of prodelphinidin B-2 3'-O-gallate from green tea leaf is through cell cycle arrest and Fas-mediated apoptotic pathway in A549 cells. Food Chem Toxicol 2005; 43: 315-323

170 Zhang $Y$, Vareed SK, Nair MG. Human tumor cell growth inhibition by nontoxic anthocyanidins, the pigments in fruits and vegetables. Life Sci 2005; 76: 1465-1472

171 Shih PH, Yeh CT, Yen GC. Effects of anthocyanidin on the inhibition of proliferation and induction of apoptosis in human gastric adenocarcinoma cells. Food Chem Toxicol 2005; 43: 1557-1566
172 Wang LS, Hecht SS, Carmella SG, Yu N, Larue B, Henry C, McIntyre C, Rocha C, Lechner JF, Stoner GD. Anthocyanins in black raspberries prevent esophageal tumors in rats. Cancer Prev Res (Phila Pa) 2009; 2: 84-93

173 Hafeez BB, Siddiqui IA, Asim M, Malik A, Afaq F, Adhami VM, Saleem M, Din M, Mukhtar H. A dietary anthocyanidin delphinidin induces apoptosis of human prostate cancer PC3 cells in vitro and in vivo: involvement of nuclear factor-kappaB signaling. Cancer Res 2008; 68: 85648572

174 Favot L, Martin S, Keravis T, Andriantsitohaina R, Lugnier C. Involvement of cyclin-dependent pathway in the inhibitory effect of delphinidin on angiogenesis. Cardiovasc Res 2003; 59: 479-487

175 Huang HP, Shih YW, Chang YC, Hung CN, Wang CJ. Chemoinhibitory effect of mulberry anthocyanins on melanoma metastasis involved in the Ras/PI3K pathway. J Agric Food Chem 2008; 56: 9286-9293

176 Fotsis T, Pepper M, Adlercreutz H, Hase T, Montesano R, Schweigerer L. Genistein, a dietary ingested isoflavonoid, inhibits cell proliferation and in vitro angiogenesis. J Nutr 1995; 125: 790S-797S

177 Barnes $S$. The chemopreventive properties of soy isoflavonoids in animal models of breast cancer. Breast Cancer Res Treat 1997; 46: 169179

178 Verma SP, Goldin BR. Effect of soy-derived isoflavonoids on the induced growth of MCF-7 cells by estrogenic environmental chemicals. Nutr Cancer 1998; 30: 232-239

179 Jung SH, Lee YS, Lee S, Lim SS, Kim YS, Ohuchi K, Shin KH. Anti-angiogenic and anti-tumor activities of isoflavonoids from the rhizomes of Belamcanda chinensis. Planta Med 2003; 69: 617-622

180 Maurich T, Iorio M, Chimenti D, Turchi G. Erybraedin C and bitucarpin A, two structurally related pterocarpans purified from Bituminaria bituminosa, induced apoptosis in human colon adenocarcinoma cell lines MMR- and p53-proficient and -deficient in a dose-, time-, and structure-dependent fashion. Chem Biol Interact 2006; 159: 104-116

181 Choi HJ, Eun JS, Kim BG, Kim SY, Jeon H, Soh Y. Vitexin, an HIF-1alpha inhibitor, has anti-metastatic potential in PC12 cells. Mol Cells 2006; 22: 291-299

182 You KM, Son KH, Chang HW, Kang SS, Kim HP. Vitexicarpin, a flavonoid from the fruits of Vitex rotundifolia, inhibits mouse lymphocyte proliferation and growth of cell lines in vitro. Planta Med 1998; 64: 546550

183 Clubbs EA, Bomser JA. Basal cell induced differentiation of noncancerous prostate epithelial cells (RWPE-1) by glycitein. Nutr Cancer 2009; 61: 390-396

184 Clubbs EA, Bomser JA. Glycitein activates extracellular signal-regulated kinase via vascular endothelial growth factor receptor signaling in nontumorigenic (RWPE-1) prostate epithelial cells. J Nutr Biochem 2007; 18: 525-532

185 Pan MH, Chen WJ, Lin-Shiau SY, Ho CT, Lin JK. Tangeretin induces cellcycle G1 arrest through inhibiting cyclin-dependent kinases 2 and 4 activities as well as elevating Cdk inhibitors p 21 and p 27 in human colorectal carcinoma cells. Carcinogenesis 2002; 23: 1677-1684

186 Lichius JJ, Thoison O, Montagnac A, Païs M, Guéritte-Voegelein F, Sévenet $T$, Cosson JP, Hadi AH. Antimitotic and cytotoxic flavonols from Zieridium pseudobtusifolium and Acronychia porteri. J Nat Products 1994; 57: 1012-1016

187 Shi Q Chen K, Li L, Chang JJ, Autry C, Kozuka M, Konoshima T, Estes JR, Lin CM, Hamel E. Antitumor agents, 154. Cytotoxic and antimitotic flavonols from Polanisia dodecandra. J Nat Products 1995; 58: 475-482

188 Dorn C, Weiss TS, Heilmann J, Hellerbrand C. Xanthohumol, a prenylated chalcone derived from hops, inhibits proliferation, migration and interleukin-8 expression of hepatocellular carcinoma cells. Int J Oncol 2010; 36: 435-441

189 Guruvayoorappan C, Kuttan G. Amentoflavone stimulates apoptosis in B16F-10 melanoma cells by regulating bcl-2, p 53 as well as caspase-3 genes and regulates the nitric oxide as well as proinflammatory cytokine production in B16F-10 melanoma cells, tumor associated macrophages and peritoneal macrophages. J Exp Ther Oncol 2008; 7: 207218

190 Aalinkeel R, Hu Z, Nair BB, Sykes DE, Reynolds JL, Mahajan SD, Schwartz $\mathrm{SH}$. Genomic analysis highlights the role of the JAK-STAT signaling in the anti-proliferative effects of dietary flavonoid 'Ashwagandha' in prostate cancer cells. Evid Based Complement Alternat Med 2010; 7: $177-187$ 
191 Guruvayoorappan C, Kuttan G. Rutin inhibits nitric oxide and tumor necrosis factor-alpha production in lipopolysaccharide and concanavalin-a stimulated macrophages. Drug Metabol Drug Interact 2007; 22: 263-278

192 Bandyopadhyay S, Romero JR, Chattopadhyay N. Kaempferol and quercetin stimulate granulocyte-macrophage colony-stimulating factor secretion in human prostate cancer cells. Mol Cell Endocrinol 2008; 287: $57-64$

193 Lee S, Kim YJ, Kwon S, Lee Y, Choi SY, Park J, Kwon HJ. Inhibitory effects of flavonoids on TNF-alpha-induced IL-8 gene expression in HEK 293 cells. BMB Rep 2009; 42: 265-270

194 Sharma V, Joseph C, Ghosh S, Agarwal A, Mishra MK, Sen E. Kaempferol induces apoptosis in glioblastoma cells through oxidative stress. Mol Cancer Ther 2007; 6: 2544-2553

195 Liu S, Ma Z, Cai H, Li Q Rong W, Kawano M. Inhibitory effect of baicalein on IL-6-mediated signaling cascades in human myeloma cells. Eur J Haematol 2009; 84: 137-144

196 Chittezhath M, Deep G, Singh RP, Agarwal C, Agarwal R. Silibinin inhibits cytokine-induced signaling cascades and down-regulates inducible nitric oxide synthase in human lung carcinoma A549 cells. Mol Cancer Ther 2008; 7: 1817-1826

197 Cortes JR, Perez GM, Rivas MD, Zamorano J. Kaempferol inhibits IL-4induced STAT6 activation by specifically targeting JAK3. J Immunol 2007; 179: 3881-3887

198 Shchemelinin I, Sefc L, Necas E. Protein kinases, their function and implication in cancer and other diseases. Folia Biol (Praha) 2006; 52: 81 100

199 Fabbro D, Ruetz S, Buchdunger E, Cowan-Jacob SW, Fendrich G, Liebetanz J, Mestan J, O'Reilly T, Traxler P, Chaudhuri B, Fretz H, Zimmermann $J$, Meyer T, Caravatti G, Furet P, Manley PW. Protein kinases as targets for anticancer agents: from inhibitors to useful drugs. Pharmacol Ther 2002; 93: 79-98

200 Teillet F, Boumendjel A, Boutonnat J, Ronot X. Flavonoids as RTK inhibitors and potential anticancer agents. Med Res Rev 2008; 28: 715-745

201 Zhang J, Yang PL, Gray NS. Targeting cancer with small molecule kinase inhibitors. Nat Rev Cancer 2009; 9: 28-39

202 Schroeter H, Boyd C, Spencer JP, Williams RJ, Cadenas E, Rice-Evans C. MAPK signaling in neurodegeneration: influences of flavonoids and of nitric oxide. Neurobiol Aging 2002; 23: 861-880

203 Virgili F, Marino M. Regulation of cellular signals from nutritional molecules: a specific role for phytochemicals, beyond antioxidant activity. Free Radic Biol Med 2008; 45: 1205-1216
204 Williams RJ, Spencer JP, Rice-Evans C. Flavonoids: antioxidants or signalling molecules? Free Radic Biol Med 2004; 36: 838-849

205 Agullo G, Gamet-Payrastre L, Manenti S, Viala C, Rémésy C, Chap H, Payrastre B. Relationship between flavonoid structure and inhibition of phosphatidylinositol 3-kinase: a comparison with tyrosine kinase and protein kinase $C$ inhibition. Biochem Pharmacol 1997; 53: 1649-1657

206 Matter WF, Brown RF, Vlahos CJ. The inhibition of phosphatidylinositol 3-kinase by quercetin and analogs. Biochem Biophys Res Commun 1992; 186: 624-631

207 Spencer JP, Rice-Evans C, Williams RJ. Modulation of pro-survival Akt/ protein kinase $B$ and ERK1/2 signaling cascades by quercetin and its in vivo metabolites underlie their action on neuronal viability. J Biol Chem 2003; 278: 34783-34793

208 Gamet-Payrastre L, Manenti S, Gratacap MP, Tulliez J, Chap H, Payrastre $B$. Flavonoids and the inhibition of PKC and PI 3-kinase. Gen Pharmacol 1999; 32: 279-286

209 Kong AN, Yu R, Chen C, Mandlekar S, Primiano T. Signal transduction events elicited by natural products: role of MAPK and caspase pathways in homeostatic response and induction of apoptosis. Arch Pharm Res 2000; 23: 1-16

210 Kumamoto T, Fujii M, Hou DX. Myricetin directly targets JAK1 to inhibit cell transformation. Cancer Lett 2009; 275: 17-26

211 Jung SK, Lee KW, Byun S, Kang NJ, Lim SH, Heo YS, Bode AM, Bowden GT, Lee HJ, Dong Z. Myricetin suppresses UVB-induced skin cancer by targeting Fyn. Cancer Res 2008; 68: 6021-6029

212 Kim JE, Kwon JY, Lee DE, Kang NJ, Heo YS, Lee KW, Lee HJ. MKK4 is a novel target for the inhibition of tumor necrosis factor-alpha-induced vascular endothelial growth factor expression by myricetin. Biochem Pharmacol 2009; 77: 412-421

213 He Z, Tang F, Ermakova S, Li M, Zhao Q, Cho YY, Ma WY, Choi HS, Bode $A M$, Yang CS, Dong $Z$. Fyn is a novel target of (-)-epigallocatechin gallate in the inhibition of JB6 Cl41 cell transformation. Mol Carcinogen 2008; 47: 172-183

214 Walker EH, Pacold ME, Perisic O, Stephens L, Hawkins PT, Wymann MP, Williams RL. Structural determinants of phosphoinositide 3-kinase inhibition by wortmannin, LY294002, quercetin, myricetin, and staurosporine. Mol Cell 2000; 6: 909-919

215 Kang NJ, Lee KW, Rogozin EA, Cho YY, Heo YS, Bode AM, Lee HJ, Dong Z. Equol, a metabolite of the soybean isoflavone daidzein, inhibits neoplastic cell transformation by targeting the MEK/ERK/p 90RSK/activator protein-1 pathway. J Biol Chem 2007; 282: 32 856-32 866 